\title{
Evaluation of HYCOM in the Kuroshio Extension region using new metrics
}

\author{
Kathryn A. Kelly, ${ }^{1}$ LuAnne Thompson, ${ }^{2}$ Wei Cheng, ${ }^{3}$ and E. Joseph Metzger ${ }^{4}$
}

Received 29 March 2006; revised 24 July 2006; accepted 5 September 2006; published 18 January 2007.

[1] A high resolution $\left(0.08^{\circ}\right.$ at equator) HYbrid Coordinate Ocean Model (HYCOM) simulation is evaluated using observations for the period 1993-2003 for a western Pacific region containing the Kuroshio Extension (KE) $\left(25-45^{\circ} \mathrm{N}\right.$ and $\left.135-180^{\circ} \mathrm{E}\right)$. Comparisons are made for the KE path and strength and for the upper ocean heat budget. The mean strength and path agree well with observations, except near the KE separation point, where the jet is as much as $2^{\circ}$ of latitude too far south. However, the model path variations are considerably more energetic than observed, and this likely obscures the observed tendency for weaker meandering when the KE is strong. The model accurately reproduces seasonal variations of upper ocean heat content, but the long-period (about 10-yr) variations of heat content and KE strength clearly differ in the region upstream of $150^{\circ} \mathrm{E}$. The long-period variations in model SSH do not show the same relationship to wind forcing that is seen in the observations and in a low-resolution ocean model simulation. The HYCOM upper ocean heat budget is similar to a diagnostic heat budget inferred from observations in that the dominant contribution is from lateral fluxes (advection); however, advection fluctuations (again primarily in the upstream region) are much larger in the model. This evaluation of HYCOM shows realistic mean quantities and realistic variations away from the separation region. However, an overly energetic jet upstream of $150^{\circ} \mathrm{E}$ can obscure the longer period variability and its contribution to the upper ocean heat budget.

Citation: Kelly, K. A., L. Thompson, W. Cheng, and E. J. Metzger (2007), Evaluation of HYCOM in the Kuroshio Extension region using new metrics, J. Geophys. Res., 112, C01004, doi:10.1029/2006JC003614.

\section{Introduction}

[2] With the increase in computational ability in recent years high-resolution eddy resolving ocean circulation simulations have been run both on the basin and global scale. These simulations have provided an amazing picture of the richness in the scales of flow in the ocean; we now have global data sets that allow us to define more precise metrics with which to evaluate the simulations. The increase in the realism of these models requires us to make more quantitative and rigorous comparisons with observations, in order to understand how well these models are reproducing ocean dynamics and thermodynamics.

[3] It is well known that western boundary currents are one of the most difficult regions of the world oceans to accurately model. The separation of the western boundary current has been a particular problem in most basin-to-global models. In low-resolution models (grid spacing larger than

\footnotetext{
${ }^{1}$ Applied Physics Laboratory, University of Washington, Seattle, Washington, USA

${ }^{2}$ School of Oceanography, University of Washington, Seattle, Washington, USA

${ }^{3}$ Joint Institute for the Study of the Atmosphere and the Ocean, University of Washington, Seattle, Washington, USA.

${ }^{4}$ Naval Research Laboratory, Stennis Space Center, Mississippi, USA.

Copyright 2007 by the American Geophysical Union. 0148-0227/07/2006JC003614\$09.00
}

about $0.1^{\circ}$ ), western boundary currents separate too far poleward, bringing warm water into the subpolar gyre whose excess heat is then fluxed to the atmosphere. For example, increasing model spatial resolution from $0.28^{\circ}$ to $0.1^{\circ}$ in a model of Gulf Stream circulation eliminates this characteristic overshoot and gives a slight southerly bias to the separation [Smith et al., 2000]. In a high-resolution ocean model for the Earth Simulator, Nonaka et al. [2006] show good agreement in the mean KE path, based on SST observations. The western boundary current separation latitude in high-resolution models has been used to evaluate what parameterizations of horizontal mixing should be used [Chassignet and Garraffo, 2001].

[4] The western boundary current provides a stringent test of an ocean model owing to the strong air-sea interaction, large heat storage, and large heat advection. Even small errors in boundary current location may result in large errors in upper ocean heat budget. An analysis of a $1 / 4 \times 1 / 4^{\circ}$ model in the North Pacific [Luo and Yamagata, 2003] demonstrates the importance of geostrophic advection of anomalous temperature in decadal variations of the upper ocean heat content; however, the authors find differences in heat content between the model and relatively coarse observations that they attribute to the overshoot of the KE separation and to problems with zonal penetration of the KE. Improving the characterization of the western boundary current makes analyses of 
the heat budgets in models more credible and allows an assessment of the implications of changes in the currents. For example, the analysis of a 54-yr run of a highresolution model [Nonaka et al., 2006] focuses on the structure and changes of both the KE and Oyashio front, showing a tendency for both fronts to migrate southward, accompanied by decreasing SST; the heat budget analysis suggests that the cooling is caused by ocean processes, not air-sea fluxes, in agreement with some previous studies.

[5] The Navy Layer Ocean Model (NLOM) has successfully simulated realistic surface currents and mesoscale features, but the use of simplified thermodynamics makes the model unusable for heat budget studies [Smedstad et al., 2003]. It has, however, been used to analyze various aspects of the circulation near and in the Kuroshio Extension (KE). For example, Hurlburt and Metzger [1998] attributed the flow bifurcation at Shatsky Rise to a mixed barotropicbaroclinic instability, combined with steering by bottom topography. Recent limited-area modeling efforts have been able to very accurately reproduce the KE [Miyazawa et al., 2004; Mitsudera et al., 2004; Tsujino and Yasuda, 2004]. However, in this model the limited domain $\left(20-52^{\circ} \mathrm{N}\right.$ and $\left.100-170^{\circ} \mathrm{E}\right)$, with boundary conditions on the edge of the domain taken from a lower resolution model, constrain the model more than basin or global simulations do. Highresolution models with full thermodynamics recently run in the North Atlantic [Smith et al., 2000] and globally [Maltrud and McClean, 2005] have allowed the evaluation of basin scale meridional heat transport with the potential to evaluate the full upper ocean heat budget.

[6] Most comparisons of high-resolution models with observations have focused on comparisons of mean properties, analyses of the SSH and SST variance, or on transport estimates at specific locations where the model may or may not perform well [Maltrud and McClean, 2005]. However, the increase in spatial resolution is likely to have the largest impact on the eddy field. In analyses of altimetric $\mathrm{SSH}$, it has been found that most of the eddy kinetic energy (EKE) in midlatitude western boundary currents can be characterized by changes in the strength and position of the meandering jet [Kelly, 1991; Qiu et al., 1991]; therefore, we focus much of the comparisons on these critical components of eddy variability, consistent with the goal of developing more precise metrics for model evaluation.

[7] In this study we examine a high-resolution simulation of the North Pacific that has complete dynamics and thermodynamics and compare its output against observations. The model used in this study, the HYbrid Coordinate Ocean Model (HYCOM), is primarily intended to be used with data assimilation to predict ocean currents and mesoscale variability, and it is anticipated that observations would correct many of the errors described here. Nevertheless, it is instructive to understand both its contributions to improving the simulation of western boundary currents and the still unresolved modeling issues. The comparison time period is from 1993-2003, based on the availability of altimetric sea surface height (SSH) and the duration of the simulation. We focus our comparisons in the $\mathrm{KE}$ region because of the difficulty that large scale ocean models have in representing the western boundary current extensions and their importance in midlatitude air-sea interactions.

\section{Ocean Circulation Model}

[8] The model used in this study is the HYbrid Coordinate Ocean Model (HYCOM) [Bleck, 2002] covering the Pacific Ocean from $20^{\circ} \mathrm{S}$ to $66^{\circ} \mathrm{N}$. The horizontal grid resolution is $0.08^{\circ}$ in longitude by $0.08^{\circ} \cos \theta$ in latitude, where $\theta$ is the latitude. This gives a midlatitude grid spacing of approximately $6 \mathrm{~km}$. It has 20 vertical coordinate surfaces that are typically isopycnal in the open, stratified ocean, but make a dynamically smooth transition to terrainfollowing coordinates in shallow coastal regions, and to z-level coordinates in the mixed layer and/or unstratified seas. The hybrid coordinate is obtained via a fully general continuity equation that allows an arbitrary partitioning between density coordinates and depth coordinates on a time step-by-time step basis. Specific details about the numerics are given by Bleck [2002], and additional case studies can be found in Chassignet et al. [2003].

[9] HYCOM is configured with several different mixed layer formulations (see Halliwell [2004] for more details), but the K-Profile Parameterization [Large et al., 1994] is used exclusively here. The bathymetry is based on a merging of ETOP05 (NOAA, 1986) and Smith and Sandwell [1997] data with numerous hand edits. Closed boundaries are used for the Indonesian Throughflow region, in the Bering Strait and at $20^{\circ} \mathrm{S}$. Along the southern boundary, temperature and salinity are relaxed to three-dimensional monthly climatological data from the Generalized Digital Environmental Model (GDEM) version 3 [Carnes, 2002] in a $3^{\circ}$-wide buffer zone. The deformation-dependent Laplacian viscosity factor is 0.1 and a combination of Laplacian (0.005) and biharmonic (0.01) momentum dissipation is used for the large and small scales, respectively.

[10] The model was initialized from a $0.16^{\circ}$ version of Pacific HYCOM and spun up at $0.08^{\circ}$ to near equilibrium using a climatology of winds and thermal forcing based on the 1979-1993 European Centre for Medium-Range Weather Forecasts (ECMWF) Reanalysis product, ERA15. After integrating 20 model years with climatological forcing, the simulation was extended using the 6-hourly 1979-1993 ERA15 Reanalysis and then 1994-2003 ECMWF operational forcing. No significant basin-wide changes in forcing were detected across the 1993-1994 time boundary. The $10-\mathrm{m}$ wind velocity components were converted to stresses using a stability dependent drag coefficient from Kara et al. [2002]. Thermal forcing includes air temperature, specific humidity and radiative (shortwave and longwave) fluxes. Precipitation is also used as a surface forcing. Surface latent and sensible heat fluxes are calculated using bulk formulae given the above atmospheric variables and model SST. Monthly river runoff is parameterized as a surface precipitation flux at a select number of locations, and oceanic turbidity is also taken into account after the work of Kara et al. [2005]. All model output used in this study are monthly averages from the last 11 years of the integration (1993-2003). The model output includes the net surface heat flux that is calculated by the model using model SST and ECMWF variables in bulk formulae of sensible and latent heat flux. No altimeter data 
Table 1. Observation Comparison Periods

\begin{tabular}{llcc}
\hline Variable & Type/Source & Times & Period \\
\hline SST & AVHRR/NOAA & $1993-2003$ & 11 years \\
SST & Microwave/RSS & $2002-2003$ & 2 years \\
SSH & Altimeter/AVISO & $1993-2003$ & 11 years \\
Flux & ERA40/ECMWF & $1993-2002$ & 9 years \\
Curl & ERA40/ECMWF & $1993-2002$ & 9 years \\
\hline
\end{tabular}

were assimilated in any of the experiments examined here, and thus we do not expect exact temporal correspondence between modeled and observed Kuroshio pathways because of mesoscale flow instabilities.

\section{Observations}

[11] The comparisons described here were made between HYCOM output and forcing fields and several observational products for the periods shown in Table 1, nominally the 11-yr period 1993-2003. The comparison region was the western North Pacific, $25-45^{\circ} \mathrm{N}, 135-180^{\circ} \mathrm{E}$.

[12] Two versions of SST observations were used in the comparisons. The longest record is the NOAA Optimum Interpolation (OI) SST V2 [Reynolds et al., 2002], a smoothed weekly product on a $1^{\circ}$ grid, commonly referred to as "Reynolds SST." The second version is the microwave SST fused product from Remote Sensing Systems, which combines data from the AMSR-E and TMI (TRMM Microwave Imager) sensors and was available from June, 2002. Because the microwave sensor can measure through clouds, the microwave SST products are potentially more accurate, despite coarser spatial resolution.

[13] For many comparisons we used the merged sea level product from Archiving, Validation and Interpretation of Satellite Oceanographic data (AVISO), which includes TOPEX/Poseidon, Jason-1, and other altimeters. The gridded product is available on a 1/3-degree grid at weekly intervals beginning in November 1992. The altimeter measures sea level, the height of the ocean surface above a reference level ellipsoid for the earth. After removing tides, the gravitational geoid, and making several corrections, the height measurements correspond to an anomaly associated with ocean dynamics, which we refer to here as sea surface height (SSH). Techniques to remove the earth's geoid generally also remove the mean SSH in the altimeter measurement; therefore, to get absolute SSH fields, it is necessary to add an estimate of mean SSH to the anomalies. Here we have used an estimate developed from hydrographic measurements by Teague et al. [1990]. (A mean SSH estimate is also available from AVISO, which combines altimeter, gravity, and ocean drifter data.) The ocean model also produces a measure of $\mathrm{SSH}$, which includes the mean.

[14] Net surface heat fluxes from an ECMWF Reanalysis (ERA40) were used in comparisons with the model heat fluxes for evaluating the model heat budget. These fluxes are readily available, but only until August of 2002. Radiative fluxes and atmospheric variables from a different ECMWF reanalysis product, ERA15, as well as from ECMWF operational forcing, were used to force the HYCOM. Discrepancies in the products and their possible impact on the analyses are noted in section 4.7. Similarly, wind stress from ERA40 was used in the analyses, whereas the stress used to force HYCOM was derived from 10-m winds using a drag coefficient and this discrepancy is noted in section 4.5 .

\section{Comparisons of Model and Observations}

[15] The start of the comparison period is set primarily by the availability of altimeter observations. The simplest and most direct comparisons are between the mean and standard deviation of the modeled and observed fields; for example, the standard deviation of SSH is used as a metric by Smith et al. [2000] for the Atlantic. A more stringent metric is the path of the western boundary current extension, which was also examined by Smith et al. [2000] using SST. We also make a comparison with (surface) current strength using the altimeter SSH anomalies and dynamic height from Teague et al. [1990].

\subsection{Sea Surface Temperature}

[16] The model SST is compared with observed temperatures using both the Reynolds and microwave fields. The location of the $21^{\circ} \mathrm{C}$ isotherm is used as a comparison point for the fields (Figure 1a): the model and observations agree well in the upstream region (west of $160^{\circ} \mathrm{E}$ ), but the model's $21^{\circ} \mathrm{C}$ isotherm is about $1^{\circ}$ too far south in the downstream region (east of $160^{\circ} \mathrm{E}$ ). Accordingly, mean SST from the model (Figure 1b) is lower than in the observed fields in the southeastern part of the region (east of $160^{\circ} \mathrm{E}$ and south of $33^{\circ} \mathrm{N}$ ) by about $0.5^{\circ} \mathrm{C}$. In the northwestern region (west of $160^{\circ} \mathrm{E}$ and north of $33^{\circ} \mathrm{N}$ ), model SST is higher by about $0.5^{\circ} \mathrm{C}$, except for a small region of negative bias centered on $35^{\circ} \mathrm{N}, 146^{\circ} \mathrm{E}$. This relatively small SST discrepancy is the result of the KE jet separating too far south, as discussed in section 4.3 .

\subsection{Sea Surface Height}

[17] A comparison of the variability of SSH (Figure 2) shows similar values for the altimeter and the model, with differences primarily in the zonal extent and latitude of the high values. For example, in the HYCOM variability (Figure $2 \mathrm{a}$ ) the $0.15 \mathrm{~m}$ contour stops at about $170^{\circ} \mathrm{E}$, whereas in the altimeter variability (Figure $2 \mathrm{~b}$ ) the $0.15 \mathrm{~m}$ contour extends beyond the eastern boundary of the study region; this weaker zonal penetration is fairly typical of ocean circulation models. In addition, in the model the region of highest values (west of $155^{\circ} \mathrm{E}$ ) occurs about $2^{\circ}$ south of the highest values in the altimeter data, suggesting that the model's jet separates somewhat too far to the south.

[18] As a way to make the SSH comparisons between the model and observations of the KE more specific, we introduce a simple way to quantify the path and strength of the KE. Assuming an approximately Gaussian profile of velocity for the core of the KE, $u(y) \approx \exp (-y / w)^{2}$, the corresponding SSH profile will resemble the integral of a Gaussian, an error function,

$$
\operatorname{erf}\left(x_{0}\right)=\frac{2}{\sqrt{\pi}} \int_{0}^{x_{0}} e^{-x^{2}} d x .
$$

This gives an expression for the $\mathrm{SSH}$ profiles in the form

$$
h(y)=A \operatorname{erf}\left(\frac{\mathrm{y}-\mathrm{y}_{\mathrm{c}}}{\mathrm{w}}\right)
$$


(a) HYCOM Mean SST and Reynolds 2^C contour

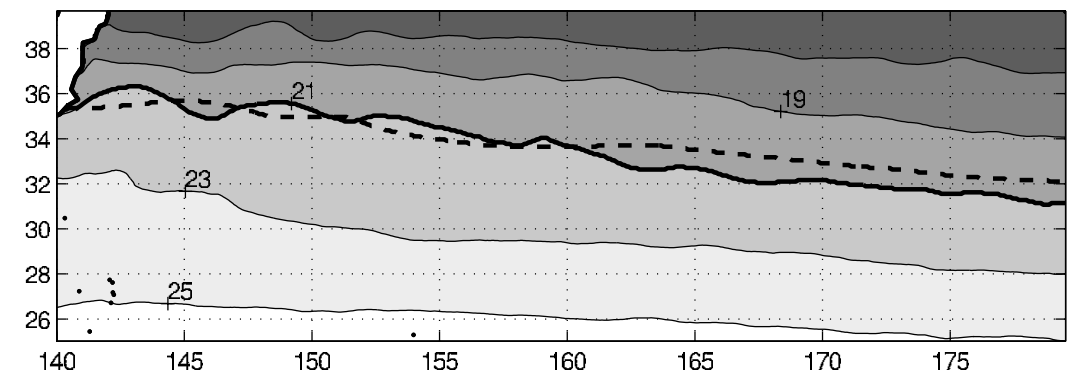

(b) HYCOM minus Observed SST

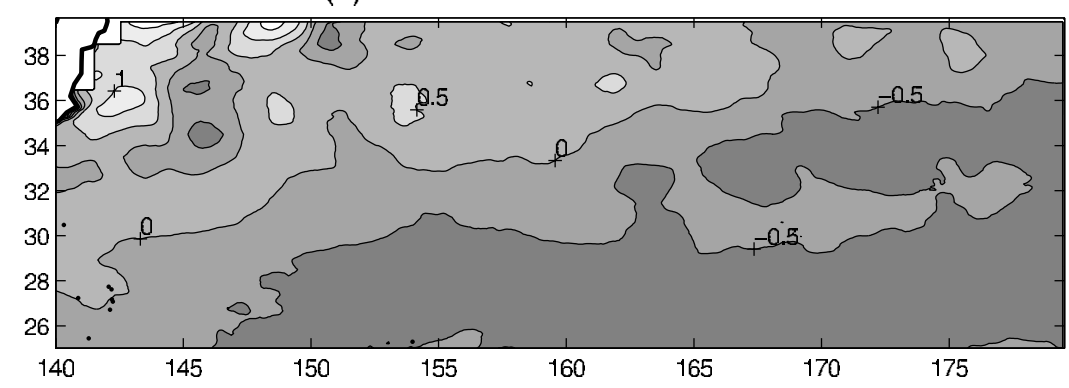

Figure 1. Comparisons of observed and modeled SST. (a) Mean of model SST and (b) model SST minus observed SST (Reynolds product). The location of the $21^{\circ} \mathrm{C}$ isotherm is shown in Figure 1a for the model (solid) and the observations (dashed).

To simplify the estimates, we fix the scale width $w$ to be $0.5^{\circ}$ of latitude, and allow only the center location $y_{c}$ and its amplitude $A$ to vary. The parameters $A$ and $y_{c}$ are adjusted to minimize the fit to the SSH in a least-squares sense over an approximately $8^{\circ}$ latitude range around the center location.
The SSH difference $\delta h$ is given by twice the amplitude $A$, and the center of the jet is given by $y_{c}$.

[19] This procedure was applied to both the model and the observed SSH to generate arrays of SSH difference $\delta h$ and the jet axis $y_{c}$ as a function of longitude and time.

a) $\mathrm{SSH}$ and path from HYCOM

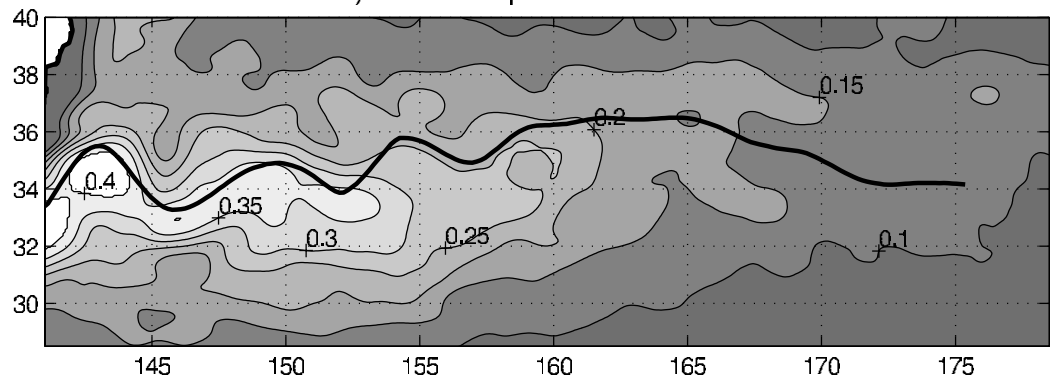

b) SSH and path from altimeter

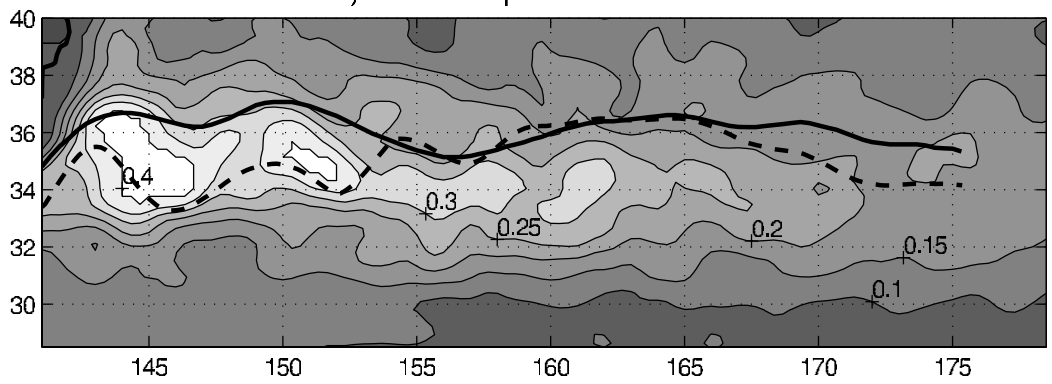

Figure 2. Comparison of SSH and Kuroshio Extension paths. Mean path (bold line) from (a) HYCOM and from (b) the mean dynamic height from Teague et al. [1990] (see text for derivation). HYCOM mean path is repeated in Figure $2 \mathrm{~b}$ as a dashed line for comparison. Paths overlaid on standard deviation of SSH from HYCOM (Figure 2a) and altimeter data for 1993-2003 (Figure 2b). Contour intervals are $0.05 \mathrm{~m}$. 
(a) HYCOM mean path (solid) and $21 \mathrm{C}$ contour (dash)

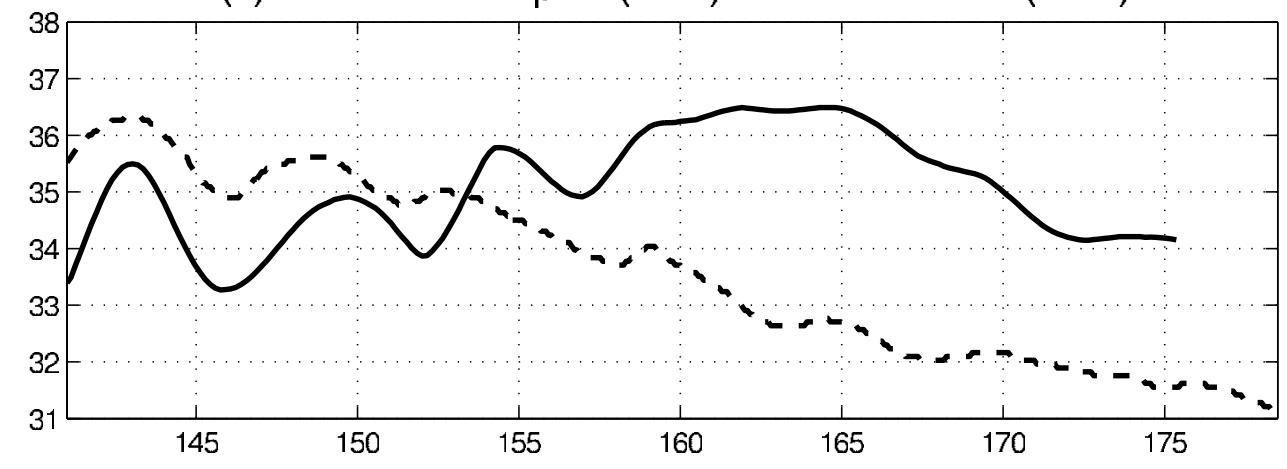

(b) Observed mean path (solid) and 21C contour (dash)

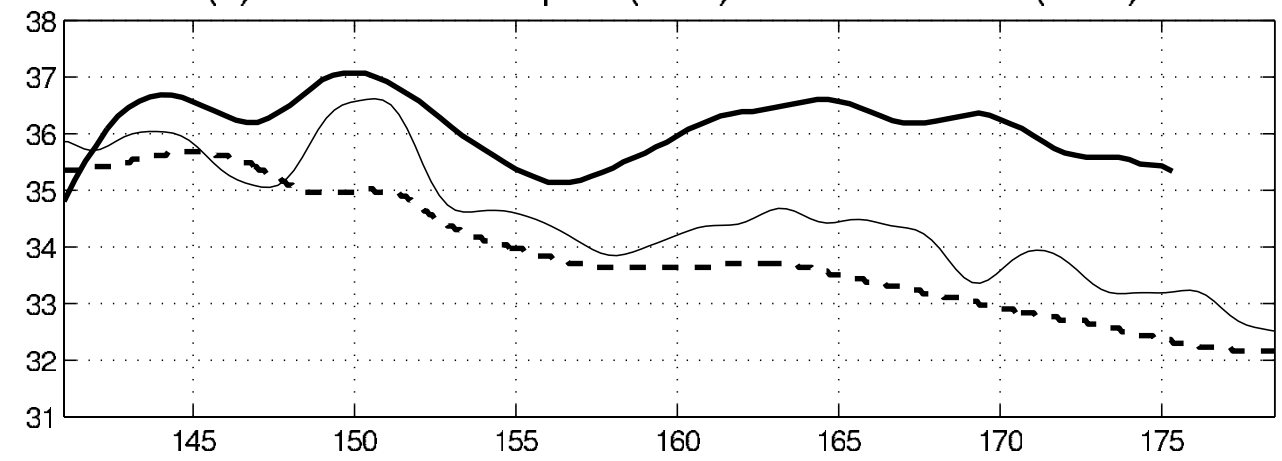

Figure 3. Kuroshio Extension path and $21^{\circ} \mathrm{C}$ isotherm. Mean axis derived from SSH (solid) and location of the $21^{\circ} \mathrm{C}$ contour (dash) from (a) the model and (b) observations. Reynolds SST was used for the dashed line in Figure $3 \mathrm{~b}$. For comparison, the location of $21^{\circ} \mathrm{C}$ isotherm from available microwave $\mathrm{SST}$ is shown as a thin line.

Note that the application of (2) to the altimeter $\mathrm{SSH}$ requires the addition of the mean sea level estimate [Teague et al., 1990] to the SSH anomaly. The nonlinear fit of the error function to $\mathrm{SSH}$ starts with an initial guess for the axis and $\delta h$, which is derived from the mean SSH field; the initial guesses were generated by fitting an error function to the mean SSH at each longitude over a latitude range of $12^{\circ}$.

\subsection{Path}

[20] The jet axis derived from the mean SSH is shown in Figure 2 for both the model and the data. The path of the model (dashed line) is repeated on the plot of observed SSH (Figure 2b) for comparison. There is good path agreement when compared to low-resolution ocean models in which the western boundary current systematically overshoots the observed separation latitude. Agreement is especially good in the central part of the region; however, the model path is south of the path from observations by approximately $2^{\circ}$ latitude upstream of $153^{\circ} \mathrm{E}$. Discrepancies of $1^{\circ}$ with the observed path east of $170^{\circ} \mathrm{E}$ are probably not significant because the jet is weak there.

[21] An alternative indicator of the current path is a fixed isotherm, although one expects that the isotherm will diverge from the jet axis as the current core cools. Here we examine the $\mathrm{KE}$ path from $\mathrm{SSH}$ in relation to a fixed isotherm as a measure of SST changes in the current core. The KE core mean SST is approximately $21^{\circ} \mathrm{C}$ at the upstream edge of our study region (Figure $3 \mathrm{~b}$ ). The iso- therm then diverges slowly from the current axis, indicating a gradual cooling of the jet core. In contrast, the model $21^{\circ} \mathrm{C}$ (Figure $3 \mathrm{a}$ ) is about $2^{\circ}$ north of the $\mathrm{KE}$ axis (but at nearly the same latitude as observed), indicating that the model $\mathrm{KE}$ is initially substantially warmer than observed. The crossing of the $21^{\circ} \mathrm{C}$ contour by the HYCOM mean KE path at about $154^{\circ} \mathrm{E}$, and subsequent more rapid divergence from the jet axis, indicates greater cooling of the KE core than observed.

[22] The similarities between the modeled and observed SST (Figure 1), despite substantial path differences in the upstream region, suggest that model's air-sea fluxes are compensating for biases in model dynamics. The fluxes will be examined in section 4.7 .

[23] The mean $21^{\circ} \mathrm{C}$ contour was also computed for the microwave SST, which was only available toward the end of the record (see Table 1). This contour (thin line in Figure 3b) shows the pair of stationary meanders in the KE at $140-150^{\circ} \mathrm{E}$, consistent with the inferred paths both from the model and altimeter SSH. This SST comparison suggests that the Reynolds SST lacks sufficient spatial resolution to describe these meanders, which are quite distinct in the SSH observations.

[24] A recent analysis of temporal fluctuations of the KE [Qiu and Chen, 2006] shows that the KE paths have periods of low and high variability in path latitude, designated "stable" and "unstable" states, respectively. Comparing the monthly paths for each of 10 years from the observed SSH (Figure 4), we can see high path coherence (a narrow 
1993
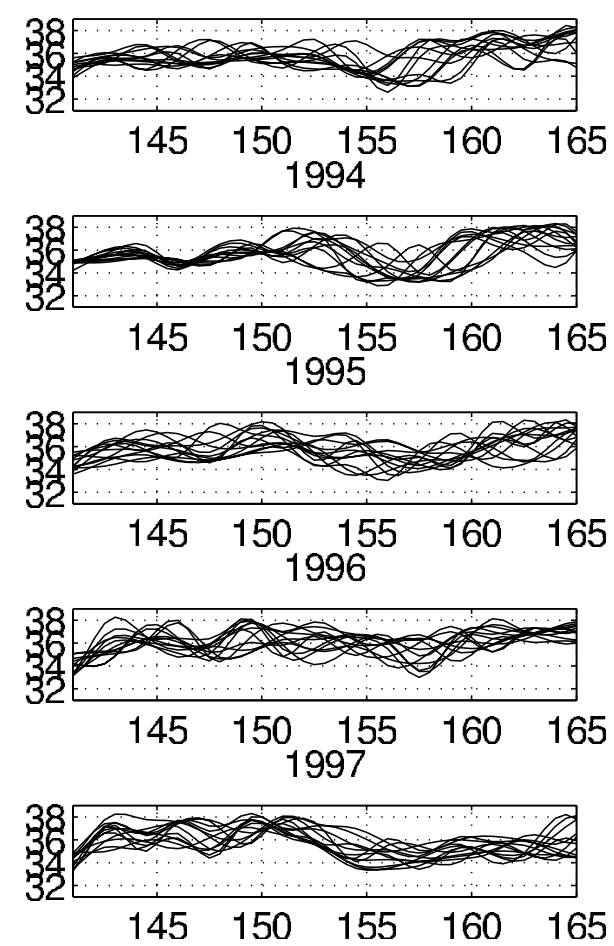

1998
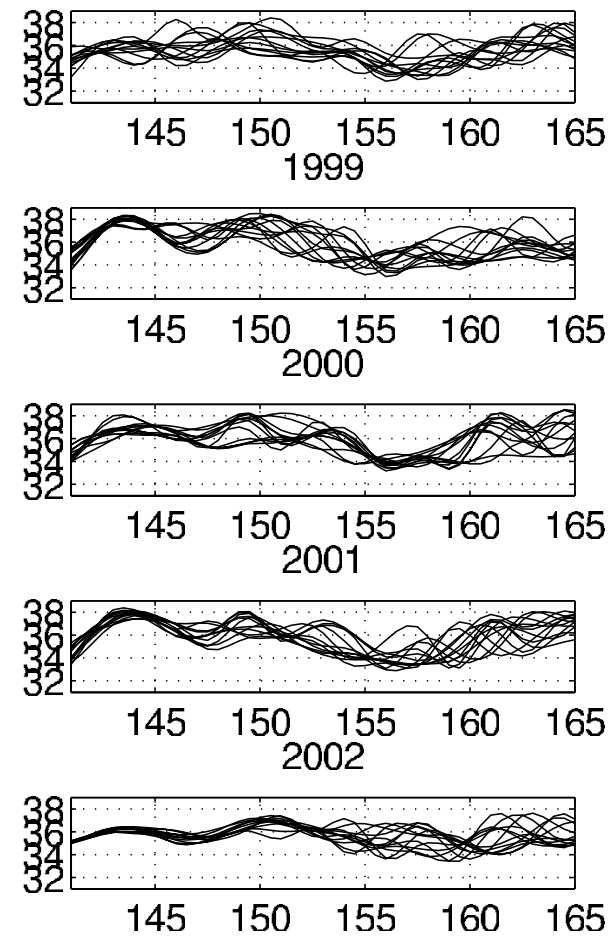

Figure 4. Paths of the Kuroshio Extension from the altimeter by year. As in Figure 5, except paths from the altimeter are interpolated to monthly intervals and to the HYCOM grid in longitude [after Qiu and Chen, 2006].

range of latitudes in a given year) particularly in 1994 and 2002, and to a lesser extent in 2001 and 1993, especially west of $150^{\circ} \mathrm{E}$. Note that the definition of KE paths used by Qiu and Chen [2006] was based on a single SSH contour, rather than the error function fit used here, but results are similar. The paths from HYCOM (Figure 5) display lower levels of stability, although with more coherent paths in 1993 and in 2001. The periods of coherent paths in the altimeter correspond generally with periods of large $\delta h$ (compare with Figure $6 \mathrm{~b}$ ), that is, with periods in which the jet is strong. An analysis of this relationship is included in section 4.4.

\subsection{Current Strength}

[25] The SSH difference across the jet, $\delta h$, is a measure of the intensity of the surface geostrophic transport, equivalent to spatially integrating the current along a meridian. Upstream of the study region, surface transport has been shown to be a good proxy for Kuroshio volume transport, based on correlations between $\delta h$ and transport estimates using current meters [Imawaki, 2001]. (However, an increase in surface transport does not necessarily imply an increase in volume transport in the Extension region, as noted by Kelly et al. [1999] in a study of the seasonal fluctuations in the Gulf Stream.) A comparison of mean $\delta h$ from the model and observations (Figure 6a) shows that the model's jet intensity is comparable to that from hydrography, based on the climatology of Teague et al. [1990]; both have a maximum value of about $0.9 \mathrm{~m}$ at $143-146^{\circ} \mathrm{E}$. Note that this measure of jet characteristics is not very dependent on resolution since we are considering the total height differ- ence across the jet over an $8^{\circ}$ latitude range. The large decrease in the strength of the eastward flowing current from $150-155^{\circ} \mathrm{E}$ indicates that much of the flow recirculates upstream of $155^{\circ} \mathrm{E}$. Overall, the mean surface current strength from HYCOM agrees well with the hydrographic observations.

[26] The error function (2) was fit at each longitude and each time to the gridded SSH to give jet strength and axis latitude. Zonal averages of $\delta h$, which represent current strength, were filtered to suppress variations with periods shorter than 3 months for the analyses described in this section, unless otherwise noted. Observed $\delta h$ (Figure 6b) reveals long-period variations: weak jet in 1994-1997, strong jet in 1993 and again in 2000-2003. (Here we will use the term long-period to refer to variations of the length of the altimetric record, about 10 years.) The time series of $\delta h$ from $\mathrm{HYCOM}$ averaged between $140^{\circ} \mathrm{E}$ and $175^{\circ} \mathrm{E}$ are not significantly correlated with the observations. Differences in the jet strength $(\delta h)$ anomalies between HYCOM and the observations are more pronounced in the upstream region; a zonal average from $146-175^{\circ} \mathrm{E}$ produces a marginally significant correlation between HYCOM and the altimeter.

[27] The long-period fluctuations seen in the observed $\mathrm{SSH}$, which are presumably related to changes in the windforced circulation of the ocean, are generally reproduced well by low-resolution models. For comparison, a $1^{\circ}$ isopycnal model (Hallberg Isopycnal Model, see Ladd and Thompson [2002] for model description) was forced with NCEP winds and the $\delta h$ anomaly from that low-resolution model is shown (thin line) in Figure $6 \mathrm{~b}$. The mean value 
1993
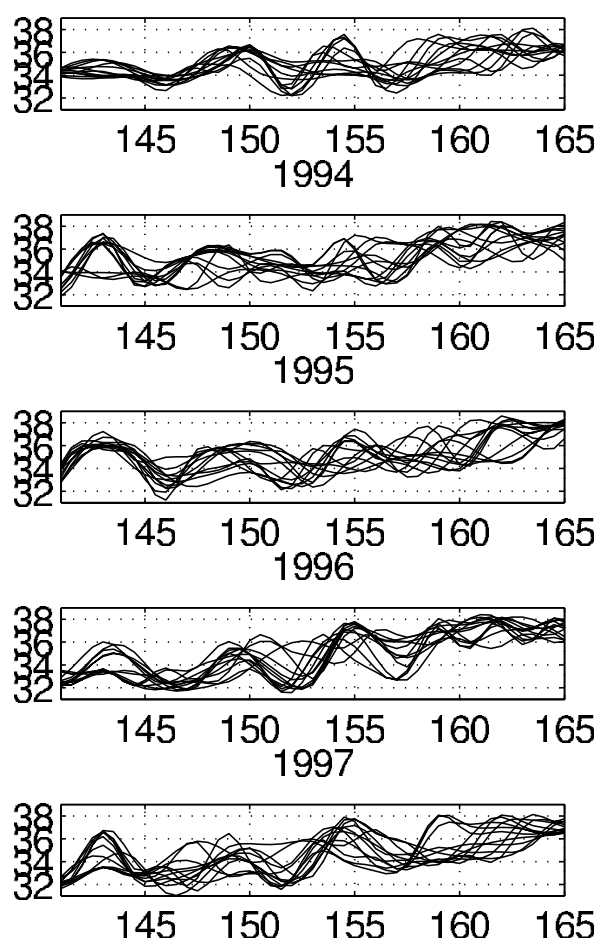

1998
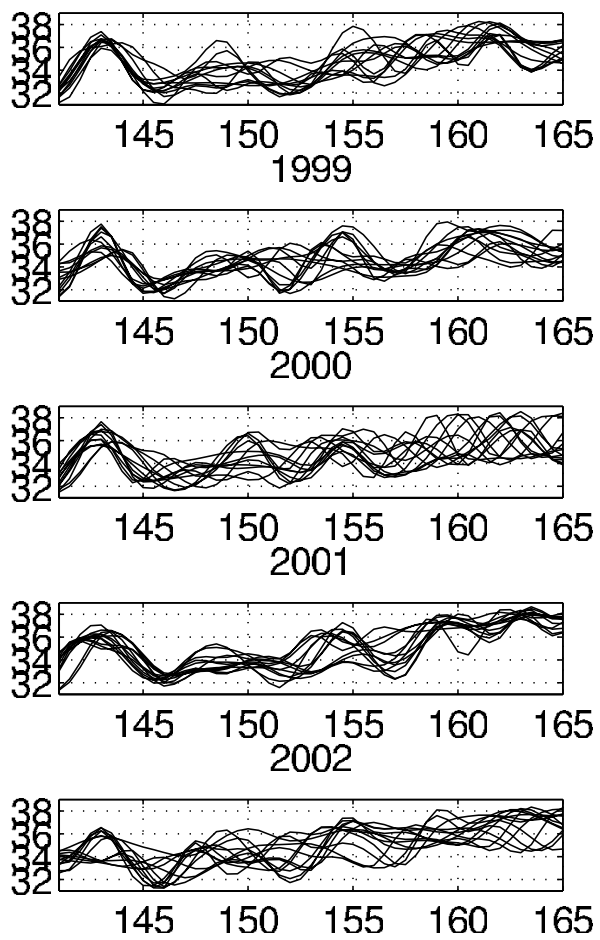

Figure 5. Paths of the Kuroshio Extension from HYCOM by year. Monthly mean axis for paths, grouped by year, for 1993-2002.

a) Mean delta-h across the Kuroshio Extension

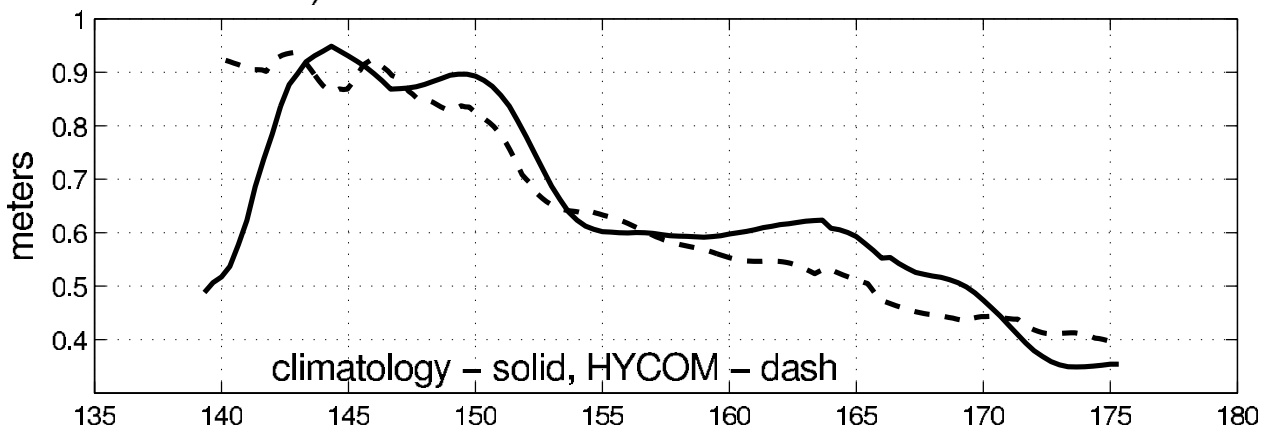

b) Mean delta-h time series

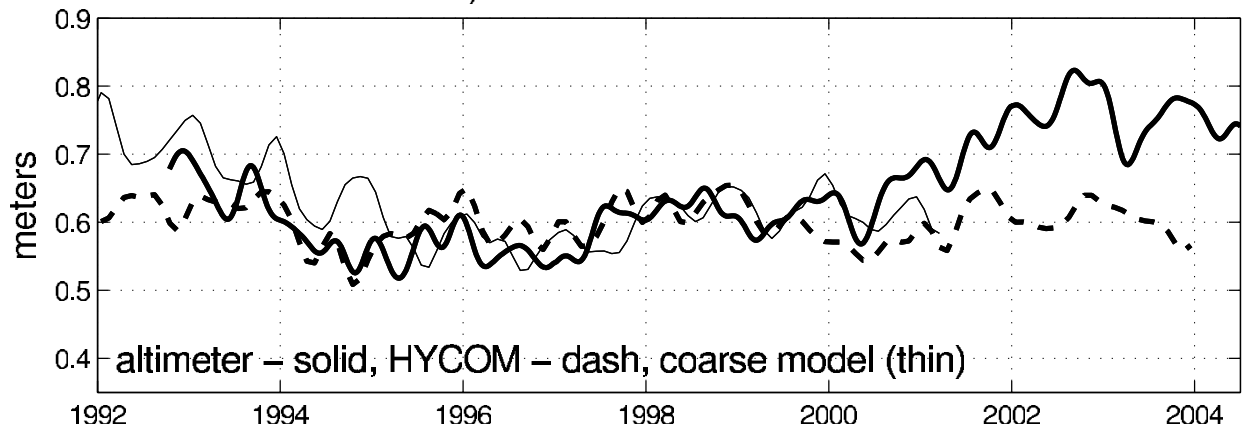

Figure 6. Model and observed mean surface current strength. (a) Temporally averaged SSH difference across the Kuroshio Extension for climatology (solid) and HYCOM (dash). (b) Spatially averaged SSH difference for altimeter (bold) and HYCOM (dash). The SSH difference time series from a $1^{\circ}$-resolution ocean model (thin line) is shown in Figure 6b. 
(a) HYCOM

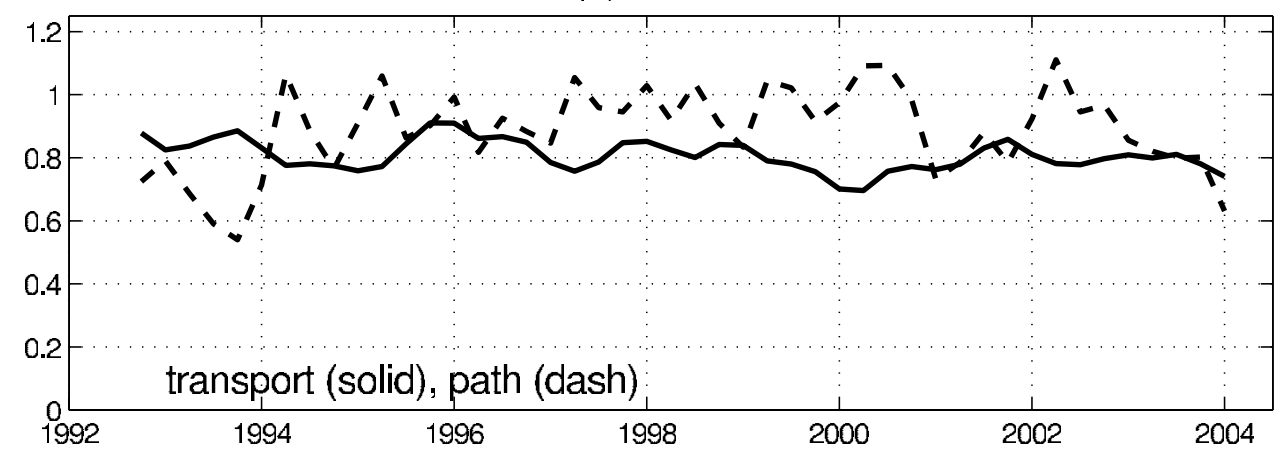

(b) altimeter

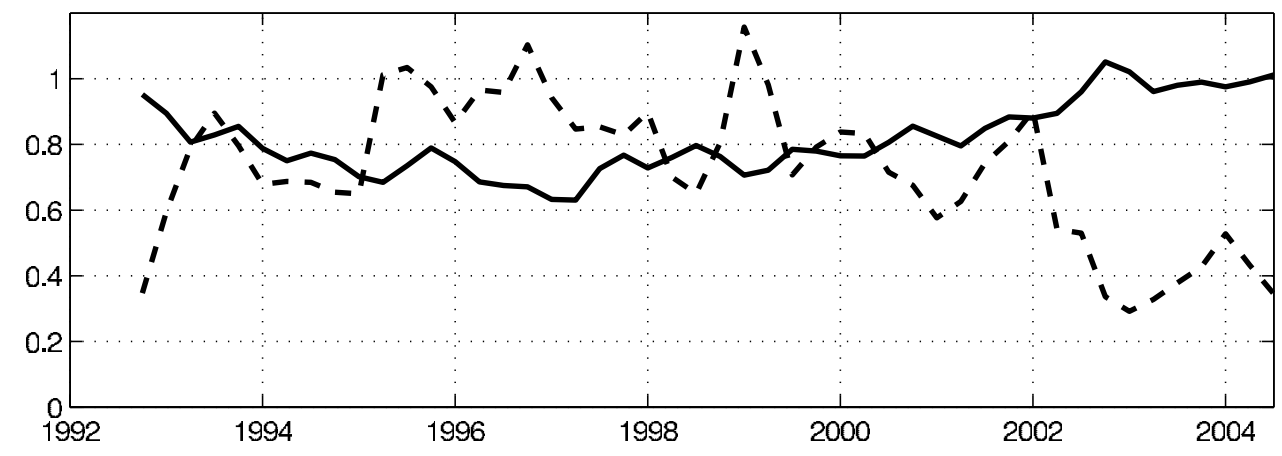

Figure 7. Model and observed SSH difference and path variability. Surface transport $\delta h$ (solid) and the standard deviation of the Kuroshio Extension path (dash) for (a) HYCOM and (b) altimeter. Values are zonal averages for the region west of $155^{\circ} \mathrm{E}$ with three-month temporal resolution.

of $\delta h$ from the low-resolution model is much larger than the value for either the observations or HYCOM, so we have shifted it downward to more nearly match the other series in Figure 6b. In the low-resolution model, we see a drop in $\delta h$ in the early 1990 s, followed by an increase in the late $1990 \mathrm{~s}$, similar to the long-period variations in $\delta h$ from the altimeter; in fact, the $\delta h$ anomalies from the lowresolution model are significantly correlated with those from the altimeter for the overlapping time period. Eddies are not resolved in the low-resolution model; thus, these comparisons suggest that the introduction of eddies in HYCOM obscure the long-period wind response in the region upstream of $146^{\circ} \mathrm{E}$.

[28] The long-period variations in current strength are mirrored by changes in the KE paths: the KE path tends to be more coherent during periods of high $\delta h$ (compare Figures 4 and 5 with Figure $6 \mathrm{~b}$ ). To quantify this relationship, we computed two statistics by seasons: the standard deviation of the path latitude and mean $\delta h$ averaged zonally over the region west of $155^{\circ} \mathrm{E}$. To obtain more reliable estimates of the standard deviation of path, we used overlapping six-month periods for each quarterly estimate. Despite the short time series (Figure 7), a significant negative correlation $(-0.84$ compared with a $95 \%$ confidence level of 0.4 ) was obtained for the altimeter; that is, stronger surface transport is correlated with a more coherent path. The HYCOM transport-path correlation was also negative, but only marginally significant $(-0.36$, compared with a $95 \%$ confidence level of 0.3 . The higher frequencies in the HYCOM time series give more degrees of freedom and therefore, a lower confidence threshold.) Despite a similar relationship between between $\mathrm{KE}$ strength and path coherence, neither the path coherence nor the $\delta h$ are significantly correlated between the altimeter and HYCOM.

\subsection{Wind-Forced Variations}

[29] Interannual variations in the KE region are likely the result of time-varying winds. Deser et al. [1999] showed that the KE fluctuations are correlated with winds in the central Pacific with a 3-4 year lag, suggestive of a timevarying baroclinic Sverdrup balance; using altimetric $\mathrm{SSH}$ Qiu [2002] had a similar result, with a somewhat longer temporal lag. Kelly and Dong [2004] found that both heat content anomalies (from 50 years of hydrographic data) and altimetric SSH were significantly correlated with wind stress curl in the western North Pacific, although with a lag of only about one year.

[30] To determine how observed and modeled fluctuations in SSH are related to winds, we compared the SSH anomalies with wind stress $[\operatorname{curl}(\tau / f)]$ from the ERA40. Following Kelly and Dong [2004], we used an empirical orthogonal function (EOF, or principal component) analysis on the $\mathrm{SSH}$ fields in the region of high variance $\left(140-160^{\circ} \mathrm{E}, 30-38^{\circ} \mathrm{N}\right.$ for the altimeter and $29-37^{\circ} \mathrm{N}$ for HYCOM). We also computed EOFs for the wind stress curl field in a larger region $\left(140-175^{\circ} \mathrm{E}, 25-45^{\circ} \mathrm{N}\right)$. Prior to the EOF analysis, the seasonal cycle (once and twice per year harmonics) was removed from SSH (curl) time series at 
(a) EOF 1 amplitude of wind stress curl

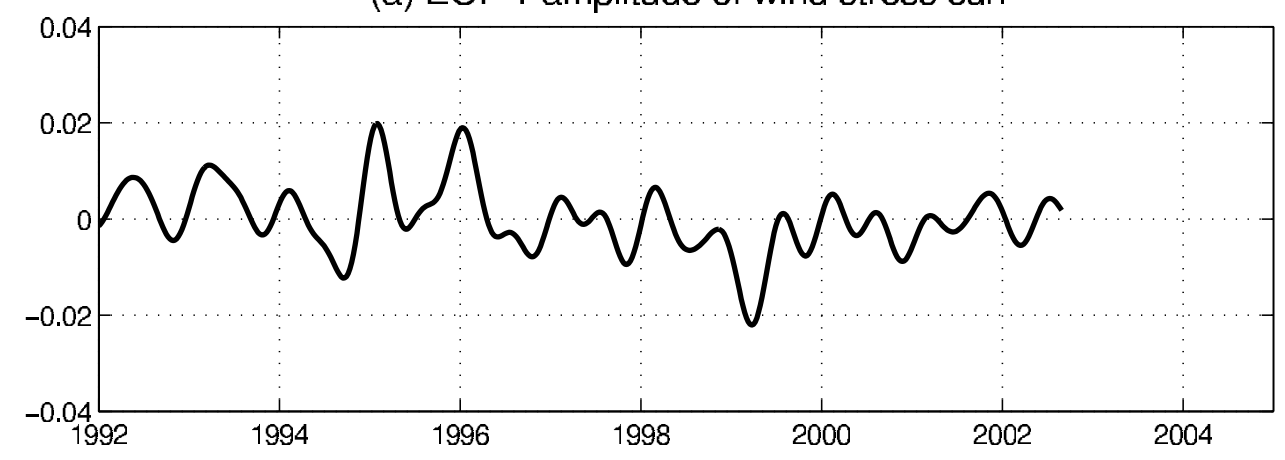

(b) EOF 1 spatial pattern

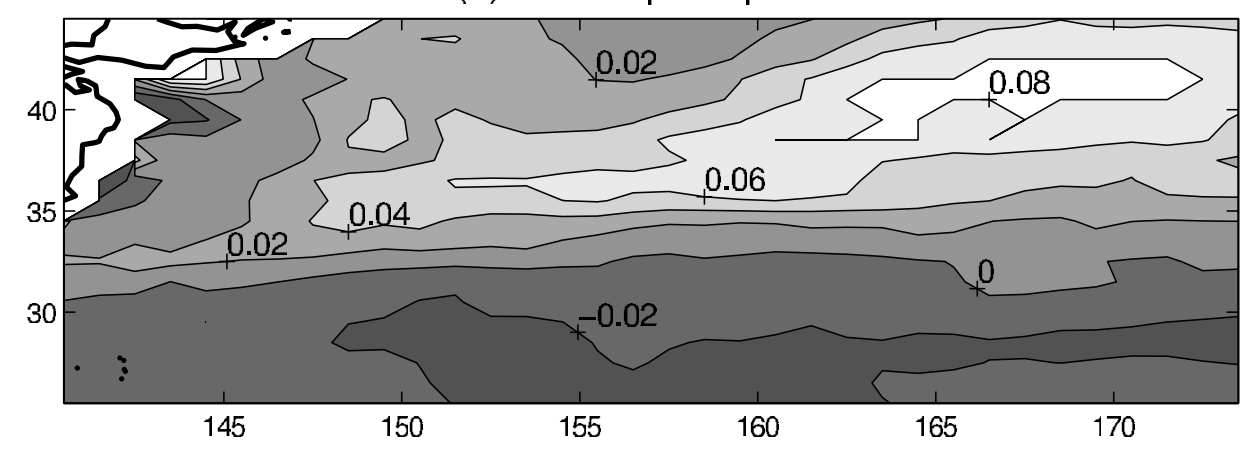

Figure 8. First mode of wind stress curl. The highest variance mode of an empirical orthogonal function analysis of wind stress $\operatorname{curl}(\tau / f)$ for the western North Pacific. Units are $\mathrm{kg} \mathrm{s}^{-1} \mathrm{~m}^{-2}$, and contour interval is 0.02 .

each location and the nonseasonal residual was filtered to reduce fluctuations with periods shorter than three (six) months.

[31] The first mode of wind stress curl (Figure 8), which contains $27 \%$ of the variance, shows that the dominant variations have a dipole pattern. In conjunction with the mean wind stress curl, which has a similar pattern but with the zero line farther north, a positive amplitude of this mode both expands and intensifies the region of positive curl in the subpolar gyre, and shrinks and weakens the negative curl region over the subtropical gyre. The first modes of altimeter and model SSH (Figures 9 and 10) contained 18 and $12 \%$ of the variance, respectively. A positive amplitude for the first SSH modes corresponds to a larger $\delta h$ across the KE. While these values do not represent a large part of the variance on times scales of a few months, the altimeter mode clearly has the distinct long-period fluctuations seen in $\delta h$ in Figure $6 b$. The model has a weaker maximum in the modal structure (Figure 10b), but relatively distinct long period variations. The time series of the $\mathrm{SSH}$ modes in the observations and in the model have a positive correlation, but it is not statistically significant.

[32] A comparison of the wind stress curl EOF time series with those from SSH shows a lagged correlation for the observations, but not for the model. A period of sustained positive amplitudes of the first curl mode (weak curl in the subtropical gyre) occurred in 1995-1996, corresponding to a period of weak KE surface transport (Figure 9a and Figure 6b). The correlation between this first mode of nonseasonal curl and altimeter SSH was -0.37 (compared with a $95 \%$ confidence level of 0.25 ) with curl leading by about 1.6 years.

[33] Correlations between the first wind stress curl mode and the HYCOM first SSH mode are not significant. The large SSH contributions of the overly energetic KE in the upstream region likely obscure the wind-forced $\mathrm{SSH}$ response. We note in section 4.4 that the HYCOM $\delta h$ time series more closely resembles the observed series when the westernmost part of the region is excluded. Discrepancies between the ECMWF wind stress products used here (see section 3) could affect the wind stress EOF; however, the lowest mode is not very sensitive to either magnitudes or the details of the fields. Most likely, the HYCOM wind-forced response is spread across several modes.

\subsection{Subtrack Analyses}

[34] The altimeter SSH data used above are derived from irregularly spaced satellite subtracks, which are separated by approximately $1-3^{\circ}$ longitude, and gridded to $1 / 3^{\circ}$ spatial resolution. To minimize the effects of regridding of SSH on model/SSH comparisons, we next compare model and altimeter SSH along satellite subtracks for a single year, 2002. We interpolate daily HYCOM SSH fields to the Jason-1 satellite tracks on the same day as the altimeter. This results in about 34 profiles per subtrack, and we examine four subtracks in detail (Figure 11a), two in the upstream (western) region and two in the downstream (eastern) region. The standard deviation of SSH along the tracks for HYCOM and the altimeter is quite similar in magnitude, consistent with the values from the gridded data 
(a) EOF 1 amplitude of altimeter SSH

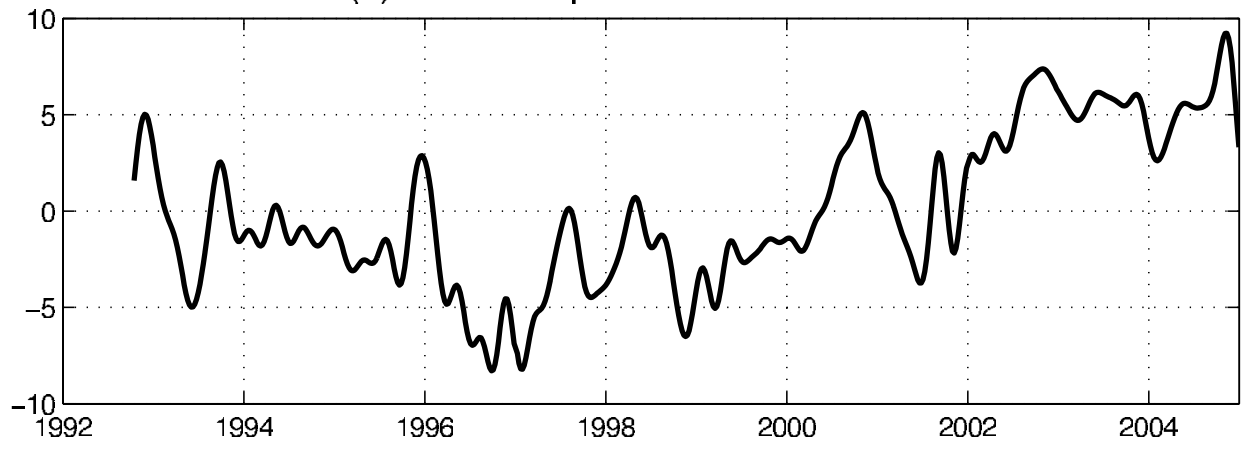

(b) EOF 1 spatial pattern

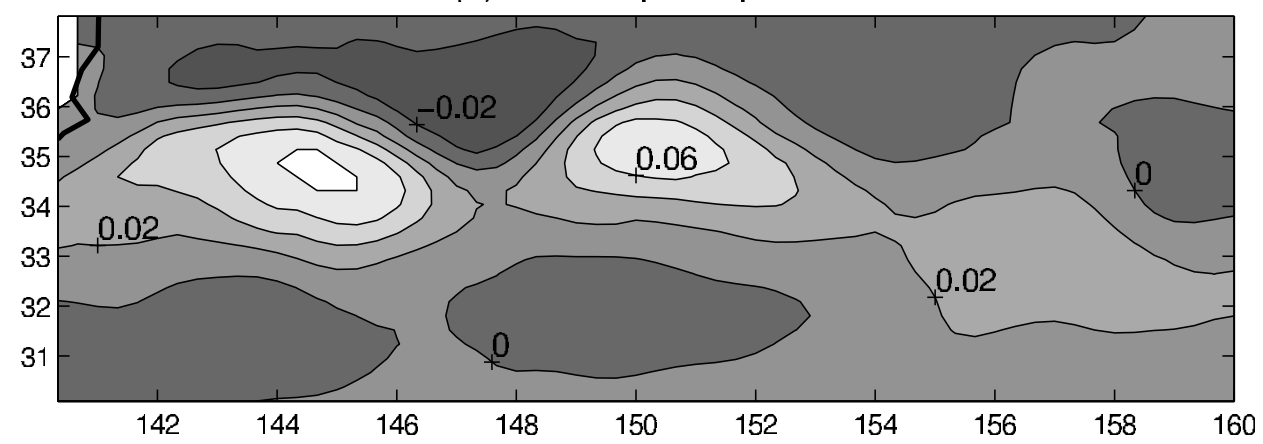

Figure 9. First mode of SSH from the altimeter. The highest variance mode of an empirical orthogonal function analysis of altimetric SSH for the western North Pacific. The contour interval is $0.02 \mathrm{~m}$.

(a) EOF 1 amplitude of model SSH

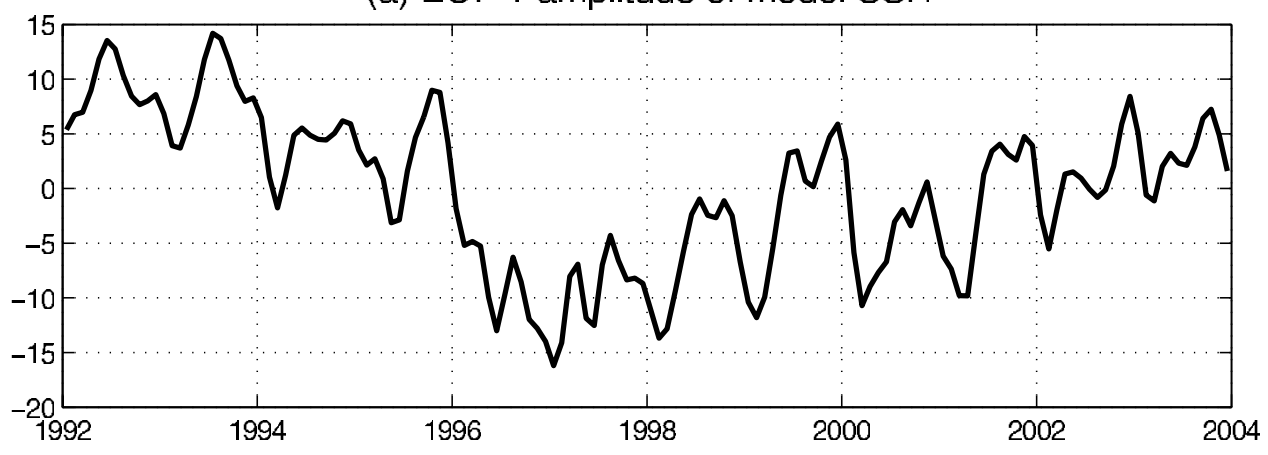

(b) EOF 1 spatial pattern

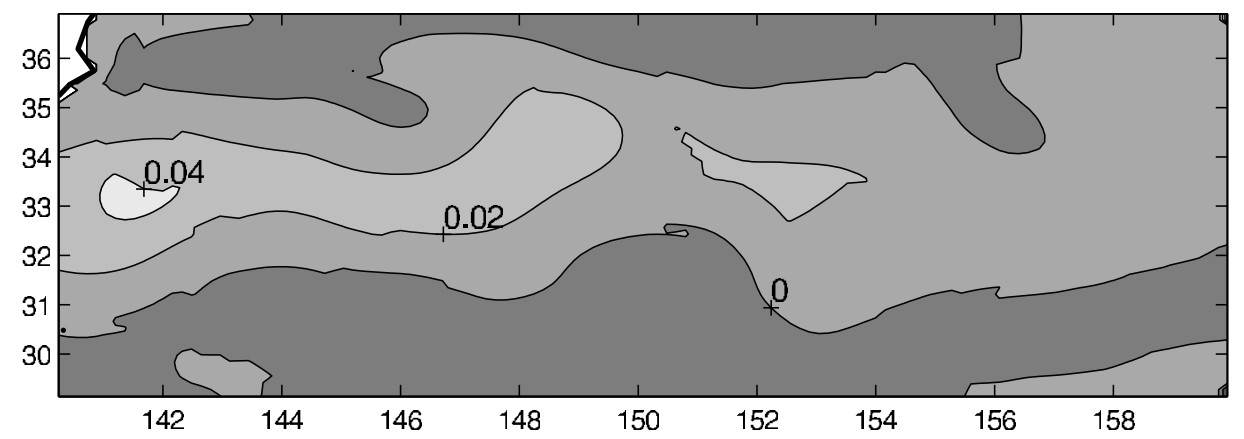

Figure 10. First mode of SSH from HYCOM. The highest variance mode of an empirical orthogonal function analysis of model SSH for the western North Pacific. The contour interval is $0.02 \mathrm{~m}$. 

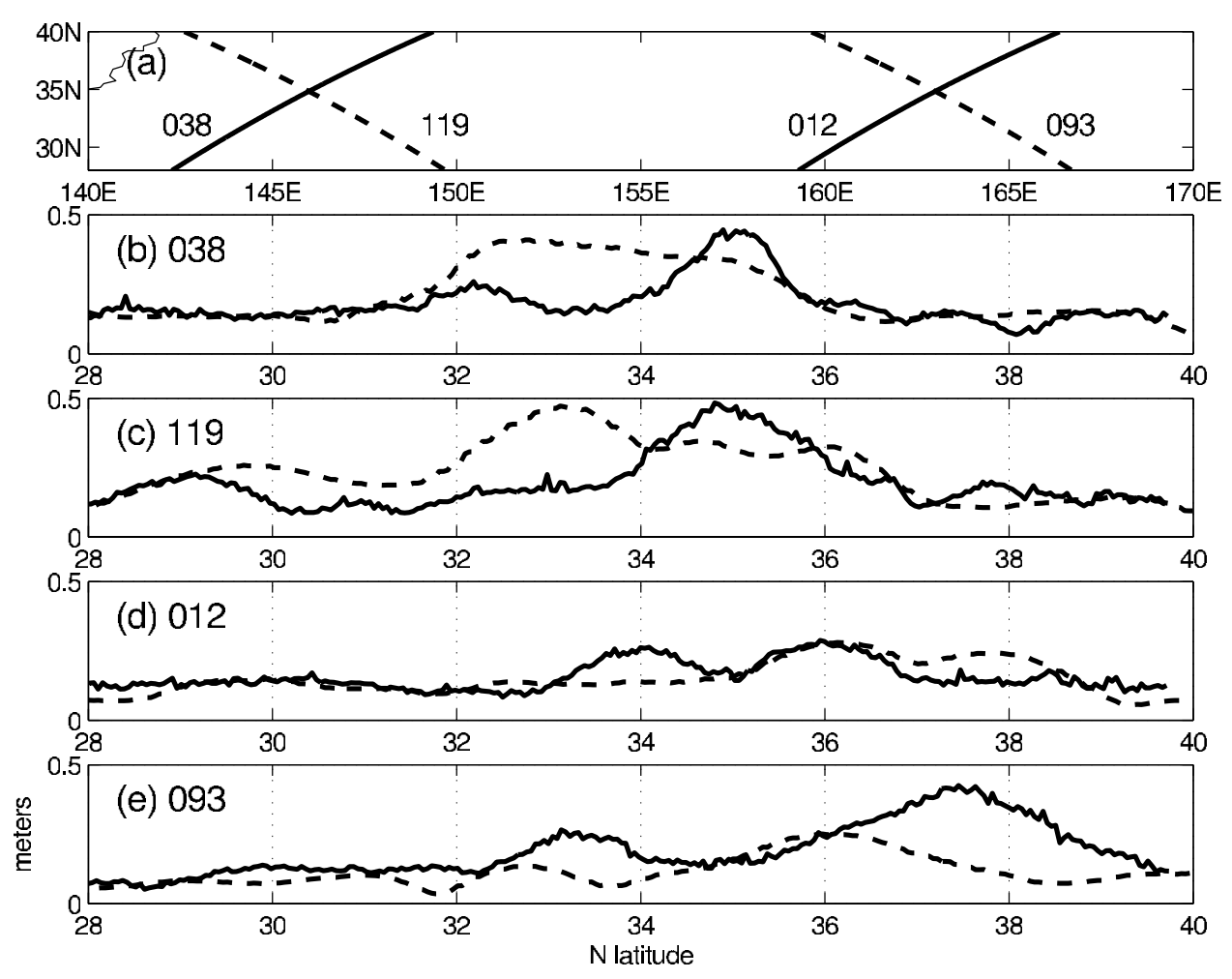

Figure 11. Model and observed SSH along satellite subtracks. (a) Ascending (solid) and descending (dash) subtracks for the western (upstream) region of the $\mathrm{KE}\left(146^{\circ} \mathrm{E}\right)$ and for the eastern (downstream) region $\left(163^{\circ} \mathrm{E}\right)$. $(\mathrm{b}-\mathrm{e})$ Standard deviation of SSH for altimeter (solid) and model (dash) for the four subtracks.

comparison in Figure 2. The peak values, which correspond roughly to the mean axis of the $\mathrm{KE}$, occur at different latitudes in the HYCOM and observed SSH, notably along track 119 (Figure 11c). A double peak in SSH variance along track 093 (Figure 11e) can be seen in both model and data, but shifted southward by $1^{\circ}$ or more in HYCOM.

[35] The distinctive double maximum in SSH variance along track 093 in both the model and the altimeter corresponds to the bifurcation of the KE near the Shatsky Rise into a northern and a southern branch at about $160^{\circ} \mathrm{E}$ [Hurlburt and Metzger, 1998]. To evaluate the model's bifurcation statistics, we fit an error function separately to each branch. Despite the two distinct variance peaks, the climatological mean SSH shows no evidence of the bifurcation, which makes resolution of two jets in altimeter SSH difficult. To facilitate the analysis, we created a new mean SSH on subtrack 093 by averaging the climatological and the HYCOM mean SSH. Taking the maximum variance regions (Figure 11e) as the first guess of the paths of the two branches of the KE, the error function was fit over a smaller $\left(3^{\circ}\right)$ latitude range along each subtrack for each branch. The range of possible latitudes for each branch overlapped to allow the two branches to merge at times.

[36] This analysis produced two sets of mean axis and $\delta h$ values along track 093 (Table 2). The mean latitudes of both the northern and the southern branch from the altimeter are, as expected from the differences in the standard deviation of SSH, farther north than in HYCOM by $1-1.5^{\circ}$. The inclusion of the HYCOM mean likely biased the jet locations from the altimeter somewhat, but the mean path locations for the altimeter and for HYCOM in Table 2 are still distinctly different. The $\delta h$ values are comparable, with the altimeter suggesting a somewhat stronger northern branch $(0.48 \mathrm{~m}$ vs. $0.36 \mathrm{~m})$. During this short record (one year) the branches are at various times separated by as much as $4^{\circ}$ in both the observations and in HYCOM or completely merged. The statistics of the bifurcation are quite similar, but the periods when the jets merge differ.

\subsection{Heat Content and Fluxes}

[37] Discrepancies between HYCOM and observed KE path and SST (Figure 3) suggest possible biases in the upper ocean thermodynamics, which we examine next using SSH (as a proxy for heat content) and air-sea heat fluxes.

[38] In addition to providing information on ocean dynamics, SSH exhibits a close relationship to upper ocean heat content [see, e.g., White, 1995]. To test this correspondence in the model, we compare time series of spatially averaged $\left(28-40^{\circ} \mathrm{N}, 140-180^{\circ} \mathrm{E}\right) \mathrm{SSH}$ and heat content (down to 400 (Figure 12a)). The mean has been removed from both and the heat content has been scaled by the

Table 2. Mean Paths and SSH Differences From Track 093

\begin{tabular}{lcc}
\hline \multicolumn{1}{c}{ Parameter } & Southern $^{\mathrm{a}}$ & Northern \\
\hline Model path, ${ }^{\circ} \mathrm{N}$ & 32.9 & 35.6 \\
Altimeter path & 34.4 & 36.6 \\
Model $\delta h, \mathrm{~m}$ & 0.36 & 0.36 \\
Altimeter $\delta h$ & 0.38 & 0.48 \\
\hline
\end{tabular}

${ }^{a}$ Shatsky Rise bifurcation: southern and northern paths. 
(a) Model heat content (solid) and SSH (dash)

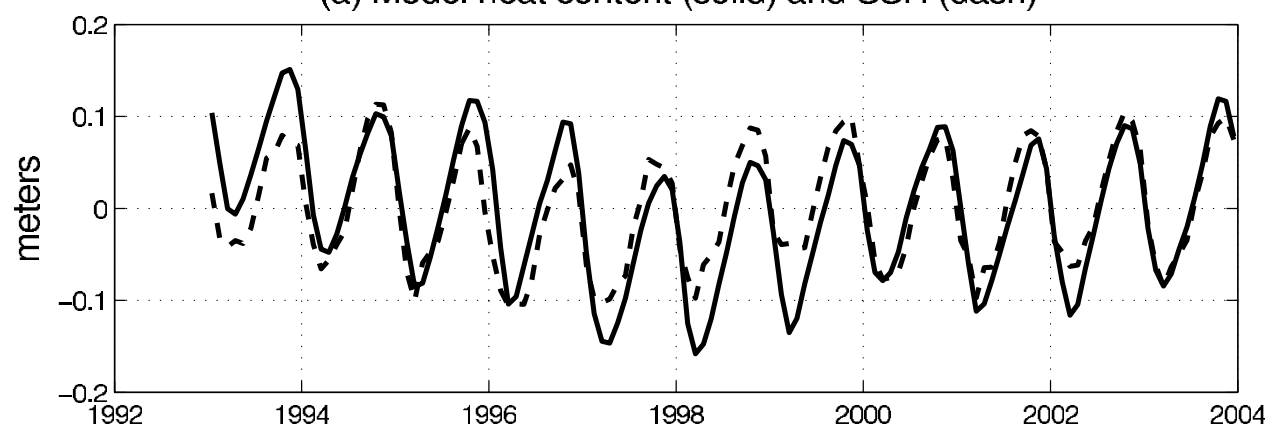

(b) SSH from altimeter (solid) and model (dash)

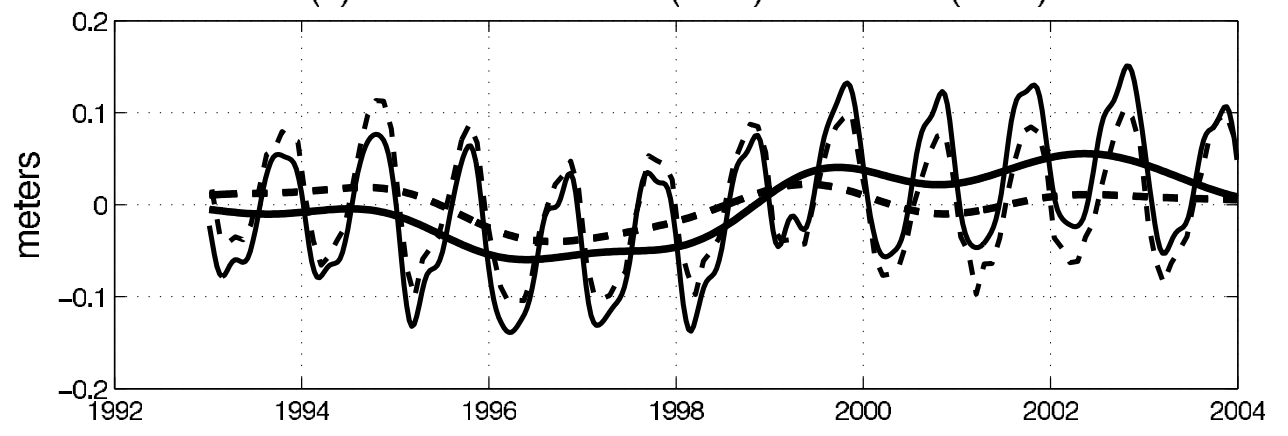

Figure 12. Comparison of heat content and SSH. (a) From HYCOM, spatially averaged SSH anomaly (dash) and heat content (solid) down to $400 \mathrm{~m}$. (b) SSH from the altimeter (solid) and from HYCOM (dash). Heavy lines in Figure 12b are the corresponding low-pass-filtered anomalies of SSH.

coefficient of thermal expansion to give a value in units of meters. Although SSH includes changes in the mass of water (rather than in its volume), as well as heat content variations below $400 \mathrm{~m}$, these contributions are small; the standard deviation of the differences between (upper ocean) heat content $\eta$ and SSH is $0.038 \mathrm{~m}$ in the model, which is much smaller than the seasonal variations. Clearly, upper ocean heat content is the largest contributor to $\mathrm{SSH}$ variations.

[39] A comparison of the domain-averaged altimetric and model SSH (Figure 12b) shows good agreement in the seasonal cycle. However, the comparison again reveals differences in the long-period fluctuations, as shown by the heavy lines in Figure 12b, which are the low-passfiltered SSH anomalies. (We have matched the mean values of SSH between the model and observations.) Altimetric SSH is lower than the model in the early part of the record (before 1999) and higher in the latter part of the record than model SSH, giving a difference of about $0.10 \mathrm{~m}$ between 1996 and 2002. This variation is not likely caused by altimeter calibration drift, which is regularly checked against a set of carefully selected tide gages [Nerem et al., 1997] and which is about a factor of ten smaller than the differences seen here (G. Mitchum, personal communication, 2004). The weaker long-period fluctuations in the model are consistent with what was seen in the $\delta h$ estimates estimates (Figure 6b). The simplest explanation for the differences is that the long-period fluctuations in upper ocean heat content are for some reason not represented well in the model. We examine this next.

[40] A likely candidate for heat content discrepancies is the air-sea heat flux. HYCOM fluxes consist of ERA15 radiative fluxes plus turbulent fluxes computed by combining ERA15 atmospheric state variables with model SST using bulk formulae. A comparison of the time-averaged model's fluxes with ERA40 net fluxes (Figure 13a) shows a picture consistent with the SST differences (Figure 1b): more heat loss (more negative flux) in the model in the northwestern part of the domain where SST is too high, and more heat gain (more positive flux) in the southeastern part of the domain, where SST is too low. Clearly, the bulk formulae are compensating for model SST errors, giving flux differences of approximately $-5 \mathrm{Wm}^{-2}$ north of the $\mathrm{KE}$ and $25 \mathrm{Wm}^{-2}$ to the south. The path bias (too far south at $143-153^{\circ} \mathrm{E}$ ) results in a surprisingly small region of positive flux differences centered at $34^{\circ} \mathrm{N}, 145^{\circ} \mathrm{E}$, corresponding to low model SST (Figure 1b).

[41] Some of the flux differences are owing to the use of different ECMWF products. A comparison of mean shortwave fluxes for ERA15 and ERA40 (not shown) for 19791993 has increased heating of the ocean by ERA40, relative to ERA15, with a difference of approximately $5 \mathrm{Wm}^{-2}$ in the northern part of the domain increasing to $15 \mathrm{Wm}^{-2}$ in the southern part. The substitution of ERA15 shortwave fluxes in our analysis would change the apparent bias of HYCOM from $-5 \mathrm{Wm}^{-2}$ to $25 \mathrm{Wm}^{-2}$ (north-to-south) to approximately $0 \mathrm{Wm}^{-2}$ in the north and $40 \mathrm{Wm}^{-2}$ in the south, but would not give a qualitative change in the mean flux difference. Another source of error is the air temperature: the mean difference in ERA15 and ERA40 air temperature is about $0.1^{\circ} \mathrm{C}$, much smaller than the $0.5^{\circ} \mathrm{C} \mathrm{SST}$ bias in Figure 1a, and therefore not likely to be its cause. Although we did not explicitly compare the ERA40 and ECMWF operational products (used for 1994-2003), we 
(a) Heat flux mean difference (HYCOM - ECWMF)

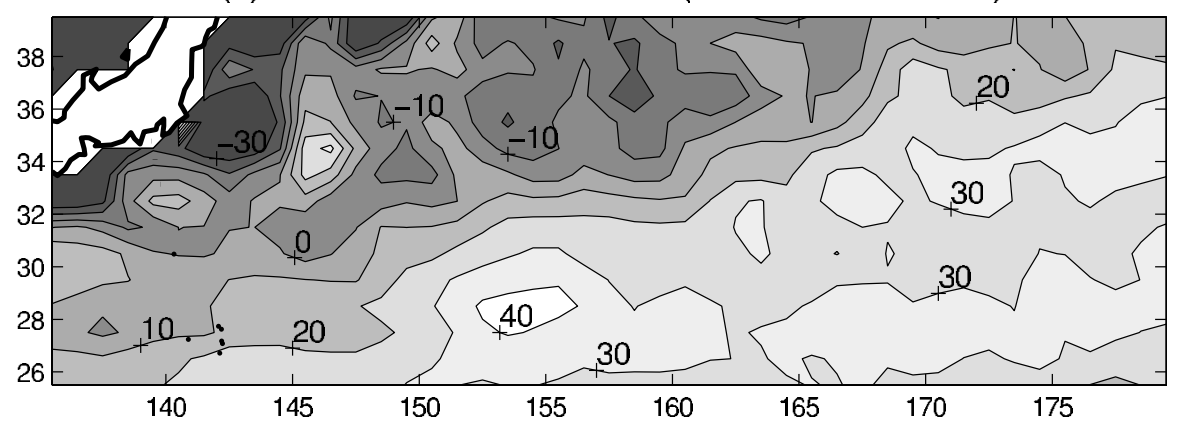

(b) SSH response to heat flux

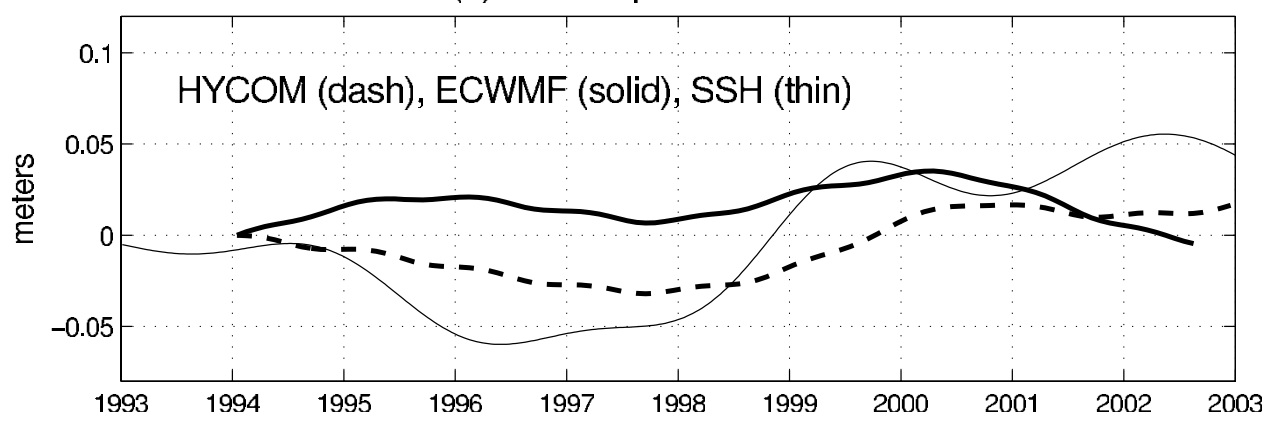

Figure 13. Comparison of net surface heat fluxes. (a) Temporally averaged net surface heat flux difference (HYCOM minus ERA40). Contour interval is $10 \mathrm{Wm}^{-2}$. (b) Contribution to SSH from heat flux for HYCOM (dash) and ERA40 (solid). Observed SSH (thin line).

would expect differences qualitatively similar to the differences between ERA15 and ERA40.

[42] To determine if surface heat fluxes are causing the long-period differences in Figure 12b, we next estimate the contribution of these fluxes to $\mathrm{SSH}$, using the domainaveraged temporally varying fluxes. In the KE region the relatively large mean loss of heat is balanced by the continual advection of warm water. Therefore, to obtain an estimate $\eta_{\text {steric }}$ of the contribution of net surface heat fluxes $Q_{n e t}$ to the $\mathrm{SSH}$ anomaly, we must first subtract from each flux time series an estimate of the mean heat flux convergence by advection and then integrate in time, as

$$
\eta_{\text {steric }}=\alpha \int_{0}^{t} \frac{Q_{n e t}-\langle a d v\rangle}{\rho c_{p}} d t
$$

Because there is no significant trend in the observed SSH over this period (Figure 12b), we assume that the mean advection exactly balances the mean flux, that is,

$$
\langle a d v\rangle=-\left\langle Q_{n e t}\right\rangle
$$

where \langle\rangle indicates a time average. Average values of $Q_{n e t}$ are significantly different: $-55 \mathrm{Wm}^{-2}$ for ERA40 and $-45 \mathrm{Wm}^{-2}$ for HYCOM, suggesting that the advection in HYCOM is weaker than what is needed to balance ERA40 fluxes. Correcting for the use of ERA40 in place of ERA15, as discussed above, the discrepancy in mean advection could be slightly larger.

[43] The estimates of $\eta_{\text {steric }}$ obtained from (3) are shown along with the observed SSH (thin line) in Figure $13 \mathrm{~b}$.
While the estimate from HYCOM (dashed line) is distinctly different from the estimate from ERA40 (solid line), we can see that the anomalies of $\eta_{\text {steric }}$ are roughly half as large as the long-period variations in observed SSH. Thus, the longperiod SSH fluctuations are not primarily caused by the approximately $20 \mathrm{Wm}^{-2}$ interannual variations in the net surface heat fluxes. Further, the lack of comparable longperiod fluctuations in HYCOM SSH is not likely the result of errors in air-sea fluxes. We next examine the role of the other terms in the upper ocean heat budget.

\subsection{Heat Budget}

[44] To investigate the discrepancies in long-period SSH variations, we compare the relative sizes of the terms in the upper ocean heat budget (the vertically integrated temperature budget). The heat storage rate down to a fixed depth $h$ is balanced by surface heating, the divergence of heat transport, and diffusion, as

$$
\frac{\partial}{\partial t} \int_{-h}^{0} T d z=\frac{Q_{n e t}}{\rho c_{p}}-\nabla \cdot \int_{-h}^{0}\left[\mathbf{u} T+\kappa \nabla^{2} T\right] d z
$$

where $h$ is larger than the wintertime mixed layer depth. Separating the terms into their vertical and horizontal components and neglecting vertical diffusion at depth $z=-h$ gives

$$
\frac{\partial H}{\partial t}=\frac{Q_{n e t}}{\rho c_{p}}-\int_{-h}^{0}\left[\mathbf{u}_{\mathbf{H}} \cdot \nabla_{H} T+\kappa_{H} \nabla_{H}^{2} T\right] d z-\left.w T\right|_{-h},
$$


(a) HYCOM

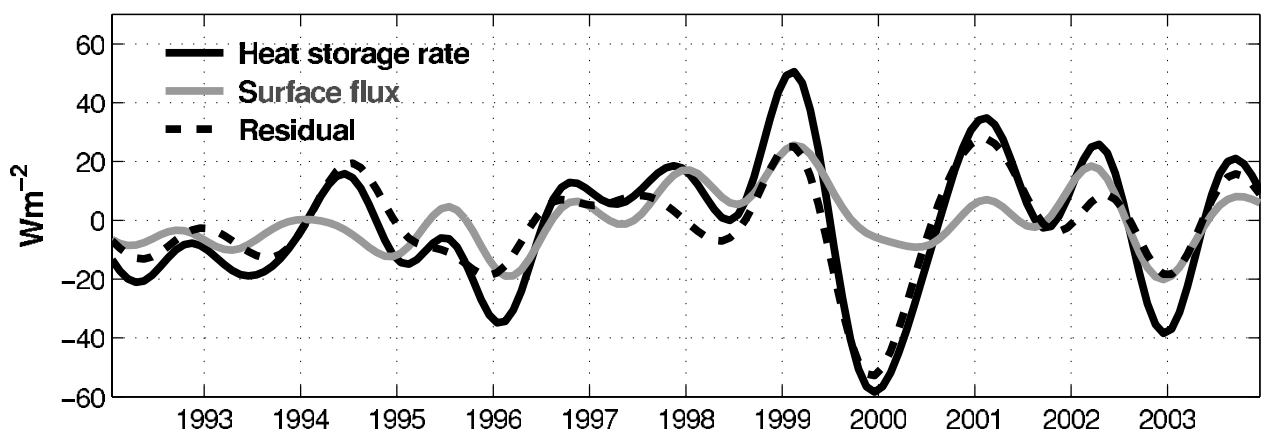

(b) Vivier et al, 2002

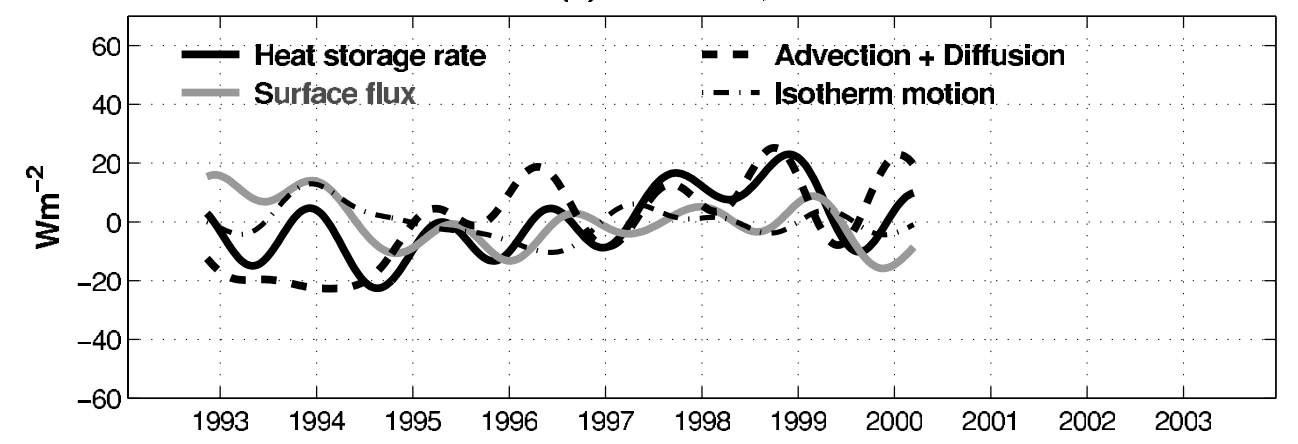

Figure 14. Vertically integrated heat budgets. Spatially averaged terms of the vertically integrated heat budget (a) from HYCOM and (b) from Vivier et al. [2002]. Heat storage rate (bold), surface flux (gray), and the residual (dashed) including advection, diffusion, and isotherm motion. In Figure 14b the residual is divided into isotherm motion (dash-dot) and advection plus diffusion (dash). Each term has been filtered to reduce variations with periods shorter than one year.

where the heat content $H$ is the vertical integral of temperature and the second term on the right-hand side in (5) is horizontal temperature advection. The last term on the right-hand side is the heat content change owing to vertical motion $w$ at depth $h$, which is the result of local convergences and divergences below the mixed layer. The HYCOM heat budget shown here (Figure 14a) consists of three terms, the heat storage rate on the left-hand-side of (5), surface flux (the first term on right-hand-side of (5)), and a residual that combines the remaining terms (to a depth of $400 \mathrm{~m})$.

[45] These same terms could be estimated directly from the observations, assuming that SSH represents heat content, but the residual would lump all sources of error together with the lateral fluxes (advection and diffusion). However, a heat budget for this region, which does close, was computed by combining horizontal velocities derived from observations and surface fluxes with a simple model of upper ocean temperature. This study [Vivier et al., 2002] produced estimates of the terms in (5) in a time period that overlaps the period of this evaluation. The study showed that most of the changes in SSH can be explained by changes in the ocean heat content in the upper $400 \mathrm{~m}$ and that, for interannual timescales, the advection of heat into the KE region is at least as important in creating heat content anomalies as are air-sea fluxes (Figure 14b). Consistent with this analysis, the heat budget from HYCOM (Figure 14a) shows that advection and diffusion are primarily responsible for interannual variations in upper ocean heat content.

[46] However, both the heat content anomalies and the advection-diffusion terms in HYCOM are considerably larger (for example, $40-60 \mathrm{Wm}^{-2}$ versus $20 \mathrm{Wm}^{-2}$ in 1999-2000) than in the Vivier et al. [2002] budget. The peak fluctuations in HYCOM heat storage have little correspondence with either observed $\mathrm{SSH}$ or the heat content variations computed from the heat budget of Vivier et al. [2002] (Figure 14b), which reproduced well the observed long-period SSH variations.

\section{Discussion}

[47] HYCOM represents a substantial improvement over low-resolution models in reproducing characteristics of the Kuroshio Extension region and there is considerable agreement between model and observations, particularly in the mean. Although assimilated observations would likely correct many model biases, the performance of high resolution models without assimilation is of great interest to the oceanographic community for use in understanding ocean dynamics and in predictions at seasonal and longer timescales. The agreement in the mean supports the idea that higher spatial resolution is necessary to simulate a western boundary current more accurately. The time-varying differences between HYCOM and observed SSH and SST suggest directions for further investigation of the model results, particularly for periods of 10 years or longer. 
[48] For much of our study region, both the mean path and the mean current strength of the KE coincide well with the observed mean path and mean current strength. Path and the strength of the KE are quantified by fitting an analytic function to the $\mathrm{SSH}$ to obtain the jet center and the $\mathrm{SSH}$ difference $(\delta h)$ across the jet axis. However, west of $153^{\circ} \mathrm{E}$ the HYCOM mean path is as much as $2^{\circ}$ too far south (Figure 2). This relatively small undershoot of the separation point for the high resolution model is similar to what was observed in a high-resolution Gulf Stream model [Smith et al., 2000]. Several viscosity sensitivity tests were performed in a $0.08^{\circ}$ Pacific HYCOM to try to improve the path of the Kuroshio Extension. No single combination of biharmonic and Laplacian diffusion gave markedly better results than other choices that could reasonably be used. Although the number of sensitivity tests was limited by computational expense, sufficient parameter space was explored to determine the model's path was not highly sensitive to the choice of viscosity.

[49] HYCOM simulates root-mean-square SSH well compared with observed SSH (Figure 2); however, it does not necessarily reproduce the temporal and spatial characteristics of the eddy field. Most of the eddy kinetic energy (EKE) in midlatitude western boundary currents is the result of the meandering jet [Kelly, 1991; Qiu et al., 1991]. One goal of this model evaluation is to develop more specific metrics than rms SSH, and therefore we focused on path and current strength statistics. We have shown that the path meanders are too energetic in the upstream region, a result similar to that of Smith et al. [2000], who found that the meander envelope of the model Gulf Stream was too large. The combination of a too-energetic jet near the separation point and a southerly path bias in both the Gulf Stream and $\mathrm{KE}$ models suggests common problems in model physics. Closely related to the overly energetic jet, there are differences in the stability of the path (Figures 4 and 5), with HYCOM having a less stable path in the upstream region, although periods of weaker meandering in HYCOM roughly coincide with the observations. Farther downstream $\left(160-165^{\circ} \mathrm{E}\right)$, there is a realistic bifurcation (though somewhat offset in the mean location) at the Shatsky Rise with timescales matching the observed timescales.

[50] In the altimeter SSH meandering is significantly anticorrelated with jet strength: stronger currents have more stable paths. The same relationship in HYCOM is discernible, but not robust, probably owing to the the HYCOM path being less stable than observed. The low-frequency and path discrepancies suggest an overly energetic KE jet west of $150^{\circ} \mathrm{E}$, which may also affect the time-varying recirculation and the heat budget; these discrepancies are less apparent farther downstream.

[51] There are other notable differences in the long-period variations in observed and modeled KE current strength, primarily in the region west of about $150^{\circ} \mathrm{E}$. Over the study domain, HYCOM has weaker long-period zonally averaged current $(\langle\delta h\rangle)$ anomalies and they are not correlated with KE current anomalies derived from the altimeter. As upstream locations are excluded from the average, beginning with the separation point of the KE, $\langle\delta h\rangle$ in HYCOM becomes significantly correlated with observations at about $146^{\circ}$ E. In addition, previous analyses [e.g., Qiu, 2002] and the observational analysis performed here show that $\mathrm{SSH}$ anomalies in the $\mathrm{KE}$ region are lag-correlated with wind stress curl; however, the HYCOM long-period fluctuations in $\mathrm{SSH}$ do not show this characteristic relationship. The wind-forced response in HYCOM is likely obscured by the overly energetic upstream region.

[52] The relatively short lag (1.6 years) between wind forcing and the observed $\mathrm{SSH}$ response raises some interesting dynamical issues. The short lag suggests an ocean response that does not simply occur by linear Rossby waves. In an examination of the adjustment of the Kuroshio Extension in a regional model, Taguchi et al. [2005] show that the acceleration of the $\mathrm{KE}$ is not explained by linear Sverdrup theory. Rather, the adjustment occurs via advection of low potential vorticity from lower latitudes and subsequent spinup of an anticyclonic recirculation. In addition, their results show a faster response to changes in the eastern boundary condition than would be expected from first mode baroclinic Rossby waves: significant $\mathrm{SSH}$ anomalies appear at the western boundary after only one year. They suggest that this may be owing to an interaction between the baroclinic and barotropic modes. On the other hand, because the wind stress EOF is computed here only over the western half of the North Pacific, the short lag may be appropriate for a baroclinic Rossby wave response over a smaller longitudinal range. However, Kelly and Dong [2004] also found a lag of one year between the Arctic Oscillation (a hemispheric measure of wind forcing) and EOFs of heat content (or SSH) in the KE and in the Gulf Steam and suggested spinup-related advection as the mechanism. The nonlinear response of western boundary currents to wind forcing is typical of what one would like to study with high-resolution models; however, the problems in the energetic upstream region suggest that this issue cannot yet be resolved using high-resolution models.

[53] There are also some discrepancies between observationally derived and HYCOM estimates of both the mean and the time-varying air-sea heat fluxes. In the mean the model ocean is absorbing more heat from the atmosphere relative to ERA40 net fluxes (positive numbers in Figure 13a) south of the $\mathrm{KE}$, corresponding to a region that is too cool in HYCOM. The relatively low HYCOM SSTs are likely associated with the weak zonal penetration of the KE, as suggested by the SSH comparison in Figure 2. However, a detailed analysis of the temperature budget was not performed and vertical processes (such as mixing and entrainment) cannot be ruled out. Air-sea heat flux differences in the region are about $20-30 \mathrm{Wm}^{-2}$, likely within the expected errors in the fluxes. In contrast, the mean path difference makes a distinct, but small, local contribution to both SST errors and flux discrepancies. SSH was used to evaluate HYCOM, as a proxy for heat content; a comparison between the altimetric and HYCOM SSH anomalies again showed problems in the long-period behavior of HYCOM. However, estimates of the contributions of airsea fluxes to SSH suggested that surface fluxes are too small to be the primary source of the discrepancy (Figure 12b).

[54] The heat budget analyses give complementary information about HYCOM performance that supports the argument that most of the discrepancies are in the upstream region. As was found in previous observationally based estimates [Vivier et al., 2002], lateral fluxes dominate the contributions to interannual variations in heat storage rate 
(Figure 14). The relatively large contribution of advection is made possible by the highly resolved currents of HYCOM; however, the residuals (lateral fluxes plus isotherm motion) are much larger than observed. To determine whether the large residuals are associated with the too-energetic changes in the upstream path, the domain-averaged heat budgets for this same latitude range $\left(30-37^{\circ} \mathrm{N}\right)$ were computed separately for upstream and downstream domains (divided at $150^{\circ} \mathrm{E}$ ). The heat storage rates and the residuals for the downstream region have magnitudes only half as large as for the upstream region, and their temporal variations more closely resemble those of Vivier et al. [2002], demonstrating that most of the discrepancies are in the upstream region. Interestingly, HYCOM residuals are anticorrelated between upstream and downstream regions, so that they tend to cancel over the larger domain.

[55] The large magnitudes of the heat storage rate, combined with the ability of a low-resolution model to simulate the observed wind-forced long-period variations in current strength $\delta h$ (Figure $6 \mathrm{~b}$ ) suggest that the addition of more eddy variability in HYCOM is obscuring the large-scale wind-forced response and its contribution to the upper oean heat budget upstream of $150^{\circ} \mathrm{E}$. This hypothesis is also supported by the low stability of the KE path compared with observations (Figures 4 and 5), indicating that the KE model jet is too turbulent.

\section{Conclusions}

[56] The impressive performance of high-resolution ocean models in simulating western boundary current extensions allows us to examine ocean processes in a way not previously possible. Although we have concentrated on the discrepancies between the HYCOM simulation and observations in the North Pacific, several aspects are particularly encouraging. Both the $\mathrm{KE}$ axis location and its mean strength (as quantified by the SSH difference across the jet) are very close to what is observed. That being said, it is in the differences between the model and the observations that we learn something. From the analysis above, it appears that the HYCOM long-period fluctuations (period of about 10 years) in jet strength are not correlated with the observed variations or with wind forcing west of about $150-155^{\circ} \mathrm{E}$, where much of the $\mathrm{KE}$ flow is recirculating. This is in contrast with results from a low-resolution model and with $\mathrm{HYCOM}$ jet strength east of $155^{\circ} \mathrm{E}$ which both reproduce the observed jet strength variations. In addition the path of the KE is less stable than in the observations and model path stability is not as clearly correlated with increasing jet strength as it is in the observations.

[57] Comparisons with observed SST show biases that are partially damped by the air-sea fluxes and are likely associated with somewhat weak zonal penetration of the KE. The approximately $10 \mathrm{Wm}^{-2}$ mean difference in the domain-averaged heat fluxes suggests an underestimate of heat advection by HYCOM into the KE region, despite the fact that the mean jet strength matches the climatological mean. In any case the surface flux discrepancies are too small to be causing the errors in long-period variations in $\mathrm{SSH}$, a proxy for heat content. An analysis of the interannual variations in the upper ocean heat budget (Figure 14) shows qualitative agreement in the relative sizes of the terms contributing to upper ocean heat content anomalies, with lateral fluxes (advection and diffusion) being primarily responsible for heat content anomalies. However, there are unrealistically large heat storage rate fluctuations originating in the region upstream of $150^{\circ} \mathrm{E}$ that are uncorrelated with the changes estimated from observations.

[58] Taken together, these comparisons with observations suggest an overly energetic jet just downstream of its (slightly too far south) separation point, creating eddy variability that obscures the longer timescale circulation in the upstream region and its contribution to heat storage rates. The similarity of this behavior to that in a Gulf Stream simulation [Smith et al., 2000] suggests a possible characteristic problem for high-resolution models.

[59] It is unclear whether a model of this type coupled to a high-resolution atmosphere would show the same biases, but it does suggest the need for a critical look at the processes that control jet separation and meander strength in any high-resolution simulation. A more realistic separation region would improve analyses of the upper ocean heat budget and of the nature of the wind-forced ocean response, as well as address other dynamical questions related to recirculation and mode water formation.

[60] From this relatively short period, it is difficult to assess the net effects of model biases (such as KE path stability) on heat content variations, air-sea fluxes, and ocean circulation, both in the mean and on decadal timescales. Errors in the forcing fields (wind stress or atmospheric variables) used in the simulation may be a factor, such that even with perfect model physics, the simulation could be in error. We await longer term coupled simulations at high resolution to determine the effects of western boundary current variations on the climate timescale.

[61] Acknowledgments. Funding for K.A.K., L.T., and W.C. was provided by the Office of Naval Research under contract N00014-96-10066 with the University of Washington. E.J.M. was supported by the 6.1 Dynamics of Low Latitude Western Boundary Currents project under program element $601153 \mathrm{~N}$ sponsored by the ONR. The numerical simulation was performed as part of the Basin-scale Prediction with the HYbrid Coordinate Ocean Model project using a grant of computer time from the Department of Defense High Performance Computing Modernization Office on the IBM SP3 computer at the Army Research Laboratory, Aberdeen Proving Grounds, Maryland. Suzanne Dickinson at APL assisted in data processing. Comments and suggestions by anonymous reviewers helped improve the analysis and the presentation of results. The AVISO altimeter products were produced by the CLS Space Oceanography Division as part of the Environment and Climate EU ENACT project (EVK2-CT2001-00117) and with support from CNES. Along-track altimeter data were obtained from Pathfinder project through the Physical Oceanography Distributed Data Archive (PODAAC). NOAA Optimum Interpolation (OI) SST V2 data were provided by the NOAA-CIRES Climate Diagnostics Center, Boulder, Colorado, USA, from their web site at http://www.cdc.noaa.gov/. The Fused Microwave SST product was obtained from Remote Sensing Systems, Santa Rosa, California, from their web site http://www.remss.com. ECMWF ERA40 data used in this study were obtained from the ECMWF Data Server.

\section{References}

Bleck, R. (2002), An oceanic general circulation model framed in hybrid isopycnic-Cartesian coordinates, Ocean Modell., 4, 55-88.

Carnes, M. (2002), Data base description for the Generalized Digital Environmental Model (GDEM-V) (U), version 3.0, U.S. Naval Oceanographic Office technical report, 27 pp., Oceanogr. Data Bases Div., Stennis Space Cent., Miss.

Chassignet, E. P., and Z. D. Garraffo (2001), Viscosity parameterization and the Gulf Stream separation, in From Stirring to Mixing in a Stratified Ocean: Proceedings of the 12th 'Aha Huliko'a Hawaiian Winter Workshop, 2001, edited by P. Muller and D. Henderson, pp. 37-41, 
Sch. of Ocean and Earth Sci. and Technol., Univ. of Hawai'i at Manoa, Honolulu. (Available at http://www.soest.hawaii.edu/PubServices/ 2001 pdfs/Chassignet.pdf)

Chassignet, E. P., L. T. Smith, G. R. Halliwell, and R. Bleck (2003) North Atlantic simulations with the HYbrid Coordinate Ocean Model (HYCOM): Impact of the vertical coordinate choice, reference pressure, and thermobaricity, J. Phys. Oceanogr., 33, 2504-2526.

Deser, C., M. A. Alexander, and M. S. Timlin (1999), Evidence for a winddriven intensification of the Kuroshio Current extension from the 1970 s to the 1980s, J. Clim., 12, 1697-1706.

Halliwell, G. R. (2004), Evaluation of vertical coordinate and vertical mixing algorithms in the HYbrid-Coordinate Ocean Model (HYCOM), Ocean Modell., 7, 285-322.

Hurlburt, H. E., and E. J. Metzger (1998), Bifurcation of the Kuroshio Extension at the Shatsky Rise, J. Geophys. Res., 103, 7549-7566.

Imawaki, S. (2001), Satellite altimeter monitoring the Kuroshio transport south of Japan, Geophys. Res. Lett., 28, 17-20.

Kara, A. B., P. A. Rochford, and H. E. Hurlburt (2002), Air-sea flux estimates and the 1997-1998 ENSO event, Boundary Layer Meteorol., 103, 439-458.

Kara, A. B., A. J. Wallcraft, and H. E. Hurlburt (2005), A new solar radiation penetration scheme for use in ocean mixed layer studies: An application to the Black Sea using a fine resolution HYbrid Coordinate Ocean Model (HYCOM), J. Phys. Oceanogr., 35, 13-32.

Kelly, K. A. (1991), The meandering Gulf Stream as seen by the Geosat altimeter: Surface transport, position and velocity variance from $73^{\circ} \mathrm{W}$ to $46^{\circ} \mathrm{W}, \mathrm{J}$. Geophys. Res., 96, 16,721-16,738.

Kelly, K. A., and S. Dong (2004), The relationship of western boundary current heat transport and storage to midlatitude ocean-atmosphere interaction, in Earth's Climate: The Ocean-Atmosphere Interaction, Geophys. Monogr. Ser., vol. 147, edited by C. Wang, S.-P. Xie, and J. A. Carton, pp. 347-363, AGU, Washington, D. C.

Kelly, K. A., S. Singh, and R. X. Huang (1999), Seasonal variations of sea surface height in the Gulf Stream region, J. Phys. Oceanogr., 29, $313-$ 327.

Ladd, C., and L. Thompson (2002), Decadal variability of North Pacific central mode water, J. Phys. Oceanogr., 32, 2870-2881.

Large, W. G., J. C. McWilliams, and S. C. Doney (1994), Ocean vertical mixing: A review and a model with a nonlocal boundary layer parameterization, Rev. Geophys., 32, 363-403.

Luo, J.-J., and T. Yamagata (2003), A model study on the 1988-89 warming event in the northern North Pacific, J. Phys. Oceanogr., 33, $1815-1828$

Maltrud, M. E., and J. L. McClean (2005), An eddy resolving global 1/10 degrees ocean simulation, Ocean Modell., 8, 31-54.

Mitsudera, H., B. Taguchi, and Y. Yoshikawa (2004), Numerical study on the Oyashio water pathways in the Kuroshio-Oyashio confluence, J. Phys. Oceanogr., 34, 1174-1196.

Miyazawa, Y., X. Y. Guo, and T. Yamagata (2004), Roles of mesoscale eddies in the Kuroshio paths, J. Phys. Oceanogr., 34, 2203-2222.

Nerem, R. S., B. J. Haines, J. Hendricks, J. F. Minster, G. T. Mitchum, and W. B. White (1997), Improved determination of global mean sea level variations using TOPEX/Poseidon altimeter data, Geophys. Res. Lett., 24, $1331-1334$

Nonaka, M., H. Nakamura, Y. Tanimoto, T. Kagimoto, and H. Sasaki (2006), Decadal variability in the Kuroshio-Oyashio Extension simulated in an eddy-resolving OGCM, J. Clim., 19, 1970-1989.

Qiu, B. (2002), Large-scale variability in the midlatitude subtropical and subpolar North Pacific Ocean: Observations and causes, J. Phys. Oceanogr., 32, 353-375.

Qiu, B., and S. Chen (2006), Variability of the Kuroshio Extension jet, recirculation gyre and mesoscale eddies on decadal timescales, J. Phys. Oceanogr., 35, 2090-2103.

Qiu, B., K. A. Kelly, and T. M. Joyce (1991), Mean circulation and variability of the Kuroshio Extension from Geosat altimetry data, J. Geophys. Res., 96, 18,491-18,507.

Reynolds, R. W., N. A. Rayner, T. M. Smith, D. C. Stokes, and W. Wang (2002), An improved in situ and satellite SST analysis for climate, J. Clim., 15, 1609-1625.

Smedstad, O. M., H. E. Hurlburt, and E. J. Metzger (2003), An operational eddy resolving 1/16 degrees global ocean nowcast/forecast system, J. Mar. Syst., 40, 341-361.

Smith, R. D., M. E. Maltrud, F. O. Bryan, and M. W. Hecht (2000), Numerical simulation of the North Atlantic Ocean at 1/10 degrees, J. Phys. Oceanogr., 30, 1532-1561.

Smith, W. H. F., and D. T. Sandwell (1997), Global sea floor topography from satellite altimetry and ship depth soundings, Science, 277, 19561962.

Taguchi, B., S.-P. Xie, H. Mitsudera, and A. Kubokawa (2005), Response of the Kuroshio Extension to Rossby waves associated with the 1970s climate regimes shift in a high-resolution ocean model, J. Clim., 18, 2979-2995

Teague, W. J., M. J. Carron, and P. J. Hogan (1990), A comparison between the Generalized Digital Environmental Model and Levitus climatologies, J. Geophys. Res., 95, 7167-7183.

Tsujino, H., and T. Yasuda (2004), Formation and circulation of mode waters of the North Pacific in a high-resolution GCM, J. Phys. Oceanogr., 34, 399-415.

Vivier, F., K. A. Kelly, and L. Thompson (2002), Heat budget in the Kuroshio Extension region: 1993-1999, J. Phys. Oceanogr., 32 3436-3454

White, W. B. (1995), Design of a global observing system for gyre-scale upper ocean temperature variability, Prog. Oceanogr., 36, 169-217.

W. Cheng, Joint Institute for the Study of the Atmosphere and the Ocean, University of Washington, Seattle, WA 98195, USA.

K. A. Kelly, Applied Physics Laboratory, University of Washington, Box 355640, Seattle, WA 98195-5640, USA. (kkelly@apl.washington. edu) E. J. Metzger, Naval Research Laboratory, Stennis Space Center, MS 39529-5004, USA.

L. Thompson, School of Oceanography, University of Washington, Seattle, WA 98195, USA. 